Elisabetta Iossa and David Martimort

The Simple Micro-Economics of PublicPrivate Partnerships

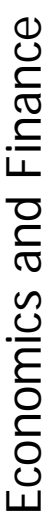

http://www.brunel.ac.uk/about/acad/sss/depts/economics 


\title{
The Simple Micro-Economics of Public-Private Partnerships ${ }^{1}$
}

\author{
Elisabetta Iossa ${ }^{2}$ and David Martimort ${ }^{3}$
}

June 13, 2008

\begin{abstract}
We build a unified theoretical framework to analyze the main incentive issues in Public Private Partnerships (PPPs) and the shape of optimal contracts in those contexts. We present a basic model of procurement in a multitask environment in which a risk-averse agent chooses unobservable efforts in cost reduction and quality improvement. We begin by studying the effect on incentives and risk transfer of bundling building and operation into a single contract, allowing for different assumptions on the contractual framework and the quality of the information held by the government. We then extend the basic model in several directions. We consider the factors that affect the optimal allocation of demand risk and their implications for the use of user charges and the choice of contract length. We study the relationship between the operator and its financiers and the impact of private finance. We discuss the trade-off between incentive and flexibility in long-term PPP agreements and the dynamics of PPP contracts, including cost overruns. We also consider how the institutional environment, and specifically the risk of regulatory opportunism, affects contract design and incentives. We conclude with some policy implications on the desirability of PPPs.
\end{abstract}

JEL Classification: D8, L5, H54, H5\%.

Keywords: Contracting out, public-private partnerships, public-service provision.

\footnotetext{
${ }^{1}$ For useful comments or discussions, we with to thank Malin Arve, John Bennett, Jérôme Pouyet, Emile Quinet, Zoe Moss and seminar participants at ESNIE (Ajaccio), at the Congrès de l' Association Française d'Economie (Paris-Sorbonne) and at the UBC P3 Project (Vancouver).

${ }^{2}$ Brunel University and University of Rome Tor Vergata, CEDI and CMPO.

${ }^{3}$ Toulouse School of Economics (IDEI and GREMAQ) and EHESS.
} 


\section{Introduction}

Under a public-private partnership (hereafter abbreviated as $P P P$ ), a local authority or a central-government agency enters a long-term contractual arrangement with a private supplier for the delivery of some services. The supplier takes responsibility for building infrastucture, financing the investment and then managing and maintaining this facility.

PPPs are being used across Europe, Canada, the US and a number of developing countries as part of a general trend seeing an increasing involvement of the private sector in the provision of public services, under the form of privatization, deregulation, outsourcing and downsizing of government. ${ }^{1}$ In 2004-5, 206 PPP contracts were signed worldwide involving 52 US $\$$ billion in investments (PWC, 2005). PPPs have traditionally been employed for example for transport, energy and water but their use has recently been extended to IT services, accommodation, leisure facilities, prisons, military training, waste management, schools and hospitals.

In Europe the PPP approach was pioneered by the Private Finance Initiative (PFI), which was launched in 1992 in the UK. ${ }^{2}$ As of December 2006, 794 PFI projects had been signed for a capital value of $£ 55$ billion (CBI, 2007). PPPs have also been in operation for more than 10 years in Portugal where investment through PPPs equalled about 20 percent of total public investment during 1999-2003. ${ }^{3}$ Other European countries have also invested in PPPs, especially Ireland, Greece, the Netherlands and Spain (EIB, 2004).

In the US, PPPs are most common for projects involving highway and road transportation, rail, and water supply and waste water treatment (CBO, 2007). The cumulative project costs of PPPs funded or completed by October 2006 totaled about $\$ 48$ billion out of nominal capital spending on infrastructure by the federal government and states and localities of $\$ 1.6$ trillion between 1985 and 2004 (averaging $\$ 80$ billion annually). ${ }^{4}$ Whilst PPPs have not accounted for a significant share of public infrastructure spending in the US so far, they are being actively encouraged by Federal Departments (DOT 2007). PPPs are also being encouraged in Canada: In November 2007 the Canadian Federal government announced a plan to promote use of PPPs and created a national fund for PPP investments of $1.26 \mathrm{CD}$.

In developing countries, PPP agreements have grown steadily since the 1990s. According to the World Bank's Private Participation in Infrastructure (PPI) database, 2750 infrastructure projects involving private and public investment for capital value of USD

\footnotetext{
${ }^{1}$ See e.g. Armstrong and Sappington (2006).

${ }^{2}$ Grout (1997).

${ }^{3}$ Välilä, Kozluk and Mehrotra (2005).

${ }^{4}$ In the US, a number of PPPs were also developed in the 70's for inner-city infrastructure (see Rosenau, 2000).
} 
786 billion have been implemented in 1990-2003 (in 2002 constant dollars). Around 1000 projects and $47 \%$ of the investment took place in Latin American and the Caribbean (LAC) countries, where Chile and Mexico were pioneers in the use of PPPs (IMF, 2004). In Central and European Countries many PPP projects were conceived in the second half of the 1990s. The PPI lists 217 projects in the region by 2003, with 64 projects for building and operating new facilities amounting to an investment of EUR 22.6b.

Despite this growth, evidence on PPP performance remains mixed. On the one hand, PFI projects in the UK seem to be delivering cost saving compared to traditional procurement. ${ }^{5}$ Improvements in completion time and cost of delivery have also been achieved; the HM Treasury (2003) reports that $76 \%$ of PPP projects have been completed on time, compared to $30 \%$ of traditionally procured projects.

On the other hand, PPPs have resulted in higher water prices than traditional procurement in France. ${ }^{6}$ PPPs seem also unsuitable for fast-moving sectors; performance failures have been widespread in PPPs for specialized IT in the UK. Existing evidence also suggests that contract renegotiations has played a pervasive role in PPP arrangements worldwide. In LAC countries numerous instances have been recorded where governments have failed to honor contract terms and projects have been abandoned. ${ }^{7}$ Adverse institutional conditions have also mattered. High transaction costs and unrealistic demand expectations have made PPPs in Central and Eastern Europe less successful than in other countries. $^{8}$

These pieces of evidence not only question the values of PPPs arrangements but also call for providing some theoretical framework to understand incentive issues in PPPs. This paper provides such unified framework and, equipped with such theoretical perspective and insights, identifies circumstances in which the main characteristics of PPP arrangements are suitable to provide adequate incentives for private contractors in infrastructure and public service provision. We also extensively describe the empirical evidence on PPPs and use our insights to derive clear policy implications.

For our purpose we characterize PPPs by three main features: (i) tasks bundling, (ii) risk transfer, (iii) long-term contract.

(i) Bundling. A PPP typically involves the bundling of the design, building, finance, and operation of the project, which are contracted out to a consortium of private firms. The consortium includes a construction company and a facility-management company and is responsible for all aspects of services. The DBFO model ('Design', 'Build' 'Finance' and 'Operate'), the BOT model ('Build', 'Operate' and 'Transfer') or the BOO ('Build', 'Own'

\footnotetext{
${ }^{5}$ Arthur Andersen and LSE (2000).

${ }^{6}$ Saussier (2006).

${ }^{7}$ Guash (2004).

${ }^{8}$ Brench, Beckers, Torsten and von Hirschhausen (2005).
} 
and 'Operate') all account for bundling of building and operation albeit with differences in degrees.

(ii) Risk transfer. Compared to traditional procurement, a PPP contract involves a greater transfer of risk and responsibility to the contractor. A system of output specifications is used: The government specifies the service it wants and the basic standards, but it leaves the consortium with control rights and responsibility over how to deliver the service and meet the pre-specified standards. So design, construction and operational risk are generally substantially transferred to the private-sector party.

(iii) Long-term contracting. A PPP contract is a long-term contract lasting typically 20 to 35 years. The payments to the private-sector party for the use of the facility is made either by the government (as in the case of PFI projects) or by the general public as users of the facility (as in more standard concession contracts).

To capture those features, we present a simple model of procurement including both moral hazard aspects and features of the property rights literature. Moral hazard is key to investigate two issues that are pervasive in the economics of PPPs. The first one is related to the existing agency costs borne by governments when delegating to the private sector the task of providing a service for society. The second one concerns risk-sharing between this government and the delegatee. A key point of the analysis is to discuss the nature of these agency costs in a multitask environment where the agent not only manages existing assets necessary to provide the service but also may design, build and finance these assets. ${ }^{9}$ Consistently with real-world practices, our model features altogether aspects of the optimal contracting literature (the verifiability of the operating costs and the need to share operating risk between the public sector and the private firm) but also dimensions of the property rights literature. We present this basic model in Section 2.

In Section 3, we use the basic model to study the conditions under which bundling of project phases (in particular building and operation) into a single contract is optimal. An important distinction that we draw is between positive and negative externalities across different stages of production. We use the term 'positive externality' (resp. 'negative externality') when a building innovation is associated with reduced (resp. increased) cost at the management stage. Bundling induces the contractors to look at the long-term performances of the asset (the so called 'whole life asset management') and this affects incentives to invest in asset quality. We shall however show that bundling improves the contractor's incentives when the externality across stages is positive but it has a negative

\footnotetext{
${ }^{9}$ In our view, this multitask aspect of the modeling is what makes the analysis of PPPs arrangements quite specific compared with the whole literature on privatization. This literature analyzes the agency cost of delegation to the private sector in a framework where a single task has to be performed by the delegatee. See the seminal papers by Sappington and Stiglitz (1987) and Shapiro and Willig (1990) for instance, and for some overviews of that approach Shleifer (1998) and Martimort (2006).
} 
or no effect when the externality is negative. Provided there is an incentive problem, our results hold regardless of the contractual framework used and of the quality of the information held by the government.

An interesting feature of optimal contracting which we emphasize is that bundling goes hands in hands with higher power incentives: When bundling is optimal, more risk is also transferred to the contractor. This provides the rationale for both bundling and risk transfer to be key features of PPP arrangements. It also explains the greater risk premium that is typically observed in PPP contracts compared to traditional procurement. Furthermore, we show that private ownership during the contract dominates public ownership and the gain from bundling with private ownership is greater for generic facilities, such as leisure centres, accommodations and public housing, than for specific facilities, such as prisons, hospitals and schools which have limited use outside the public sector.

Once equipped with the rationale for bundling and risk transfer in PPP agreements, we develop our basic insights in more elaborated environments which have been viewed as particularly interesting both in the public debate and within recent academic research.

Section 4 deals with the issue of risk transfer in more depth by analyzing how demand risk should be optimally shared between the private and public partners. We then analyze some of the factors that affect the optimal allocation of demand risk and derive their implications for users charges and the choice of contract length. We also discuss the case of financially-free standing projects where users' fees represent all of the contractor's revenue. This allows us to discuss another important characteristic of many PPP arrangements, namely the use of private finance and its impact on contract length and incentives.

Section 5 makes a powerful extension of our basic model that provides the basic relationship that operator and financiers may entertain under a PPP agreement. This issue is of tantamount importance given the estimated size of investments in infrastructures that is forecasted for the next twenty years, and the role that infrastructure funds will thus play. ${ }^{10}$ We show that outside finance may improve risk-allocation if it helps alleviating moral hazard and that transaction costs of outside finance are relatively weak.

Long-term contracts also suffer from uncertainty over the future evolutions of users' needs. This might make them unsuitable in circumstances where users needs evolve rapidly and the output specifications set up in the initial contract become quickly obsolete. We discuss this cost of PPP contracts in Section 6. We argue that, for fast-moving sectors, the benefit of bundling needs to be weighted against the cost of contract rigidity. This cost may be severe enough to make PPPs unsuitable when users needs evolve rapidly.

Section 7 analyzes how long-term agreements are subject to contractual hazards es-

\footnotetext{
${ }^{10}$ Levita (2008) reports that those needs are up 2500 millions U.S. dollars overall among which one fifth will be invest in "greenfields" projects.
} 
pecially in view of incentivizing investment over the length of the contract. We start by considering the case of a public authority having a strong commitment power; the risk of unilateral changes of contract terms by governments is then minimal. The optimal longterm contract entails increasing incentives over time to foster the renewal of investment. Cost-plus contracts arise in early periods whereas fixed-price agreements are expected close to the end of the contract duration.

Long-term contracts however suffer from being signed in contexts where uncertainty over the realizations of future demand and cost levels is pervasive. When estimates turn out to have been optimistic, renegotiation of contract terms may occur, partially nullifying the incentive power of the initial contract. We then extend our analysis of the dynamics of PPPs by considering the distortions that are needed to prevent cost-overruns. Incentives should be tilted towards being low-powered and less risk should be transferred at earlier stages of contracting. However, this non-stationarity of incentives does not necessarily undo the benefits of bundling.

Section 8 analyzes how the institutional environment, and most specifically the risk of regulatory opportunism, affects contract design and incentives. We consider thus settings where the risk of unilateral changes of contract terms by governments is significant. This typically might depict developing countries with weak governances but, beyond, the kind of political uncertainty that we have in mind certainly has a broader appeal even for developed countries subject to the political risk that electoral uncertainty generates. Relaxing the assumption of full commitment, we discuss the importance of institutional quality. We show that, in such environments, cost-plus contracts should be preferred. This of course reduces the benefits of bundling without again coming to the conclusion that bundling should be given up.

Section 9 summarizes our conclusions and discusses the scope for future research. ${ }^{11}$

Proofs not provided in the text are relegated to an Appendix.

\section{A Bare-Boned Model}

We consider the following public procurement context: A government (thereafter the principal sometimes refereed to as $G$ ) relies on a private firm or consortium (the agent $F)$ to provide a public service for society. Examples of such delegation include of course transportation, water production and sanitation, waste disposal, etc. In such settings, providing the service can only be done if an infrastructure of a sufficiently good quality has been first designed and built. Clearly, this delegation of services towards the private

\footnotetext{
${ }^{11}$ One omitted domain of investigation for this paper is the macro-economic/public finance side of PPPs. On this issue we refer to Välilä (2005), Välilä, Kozluck and Mehrotra (2005) and Sadka (2005).
} 
sector must be modeled as a multi-task problem. ${ }^{12}$ The main feature of a PPP can then be viewed as the bundling of various phases of contracting. Typically the design (D), building (B), finance $(\mathrm{F})$ and operation $(\mathrm{O})$ of the project (this is the so-called "DBFO model") are contracted out to a consortium of private firms. This consortium is made of at least a construction company and a facility-management company and it is responsible for all aspects of service. ${ }^{13}$

By exerting a quality-improving effort (or, in an alternative interpretation of our model that will be sometimes used thereafter, making some investment in the quality of the infrastructure), the agent improves the quality of public service. The corresponding social benefit is worth

$$
B=b_{0}+b a
$$

where the marginal benefit of the agent's effort is positive $(b>0)$ and $b_{0} \geq 0$ denotes some base level for the benefits of the service that is obtained even without any effort. We also assume that the social benefit is hardly verifiable.

Providing the service costs to the firm an amount

$$
C=\theta_{0}-e-\delta a+\varepsilon
$$

The random variable $\varepsilon$ is normally distributed with variance $\sigma^{2}$ and zero mean. It captures any operational risk that the firm may incur when managing the asset. $\theta_{0}$ is the innate cost of the service (linked to the technology used) and $e$ is the agent's effort in cost-reducing activities.

Two alternative scenarios will be particularly analyzed in the sequel. The case $\delta>0$ corresponds to a positive externality where improving the quality of the infrastructure also reduces the operational costs. For example, the design of a prison with better sightlines for staff that improve security (i.e., social benefit) may yield the positive externality that the required number of security guards is reduced. The case $\delta<0$ corresponds to a negative externality where improving the quality of infrastructure increases operational costs. For example, an innovative design of a hospital, using recently-developed materials, may lead to improved lighting and air quality, and therefore better clinical outcomes, but may also increase maintenance costs.

Quality-enhancing and operating efforts have monetary costs for the agent. For simplicity, these costs are respectively given by the quadratic disutility functions $\varphi(a)=\frac{a^{2}}{2}$ and $\psi(e)=\frac{e^{2}}{2}$. There are no (dis-)economies of scope between efforts.

Delegation of services to the private sector takes place in a moral hazard environment

\footnotetext{
${ }^{12}$ Holmström and Milgrom (1991).

${ }^{13}$ Variations of the DBFO contract include Design-Build-Operate (DBO), Build-Operate-Transfer (BOT), Build-Own-Operate-Transfer (BOOT), Build-Lease-Operate-Transfer (BLOT), etc...
} 
so that both $a$ and $e$ are nonverifiable. Only the operating cost $C$ is observable and can be used ex ante at the time $G$ and $F$ contract together. Consistently with many examples of PPP projects, the social value of the project is hardly contractible and no related statistics even a rough one can be used to condition payments on realized social value. Moreover, both the government and the firm are ignorant of the realization of cost uncertainty. ${ }^{14}$

The risk-neutral government $G$ is supposed to maximize an expected social welfare function, defined as the social benefit of the service net of its costs and of the payment made to $F .^{15}$ The firm $F$ also maximizes his expected utility and is risk-averse with constant degree of risk-aversion $r>0$. This captures the fact that a PPP project might represent a large share of this firm's activities so that the firm's activities can hardly be viewed as being fully diversified.

- Benchmark: For future references, it is worth describing the first-best levels of effort $a^{F B}$ and $e^{F B}$ that would be achieved had those efforts been observable and contractible. At the first-best, the risk-averse agent is of course fully insured by the risk-neutral government through a cost-plus contract. Given that the public authority can run a competitive auction to attract potential service providers, we assume that it has all bargaining power ex ante and chooses a fee for the service provider that makes him just indifferent between producing the service or getting his outside option normalized at zero. Moreover, that contract also forces the firm to choose the first-best efforts defined as:

$$
\left(a^{F B}, e^{F B}\right)=\arg \max _{(a, e)} b_{0}-\theta_{0}+(b+\delta) a+e-\frac{a^{2}}{2}-\frac{e^{2}}{2}=(b+\delta, 1) .
$$

The first-best quality-enhancing effort $a^{F B}$ trades off the marginal social value of that effort, including its impact on operating $\operatorname{costs}(\delta)$ and on the social value of the service $(b)$, with its marginal cost $(a)$. The operating cost-reducing effort $e^{F B}$ trades off the marginal benefit of lowering those operating costs (1) with its marginal monetary disutility $(e)$.

- Timing: The contracting game unfolds as depicted by means of the following time line.

\footnotetext{
${ }^{14}$ Focusing on such moral hazard environment fits well with the observation made by Bajari and Tadelis (2001) that, in many procurement contexts, the buyer and the seller face the same uncertainty on costs and demand conditions.

${ }^{15}$ The assumption of risk-neutrality for the government gives a simple benchmark: In the absence of moral hazard, optimal risk allocation requires that the public sector bears all risk. This assumption may be questioned in the case of a small local government whose PPP project under scrutiny represents a significant share of the overall budget. In the case of a large country's government, the existing deadweight loss in the cost of taxation may as well introduce a behavior towards risk if the PPP project were to represent a large share of the budget (Barro (1990)). Lewis and Sappington (1995) and Martimort and Sand-Zantman (2007) analyze the consequences of having risk-averse local governments.
} 


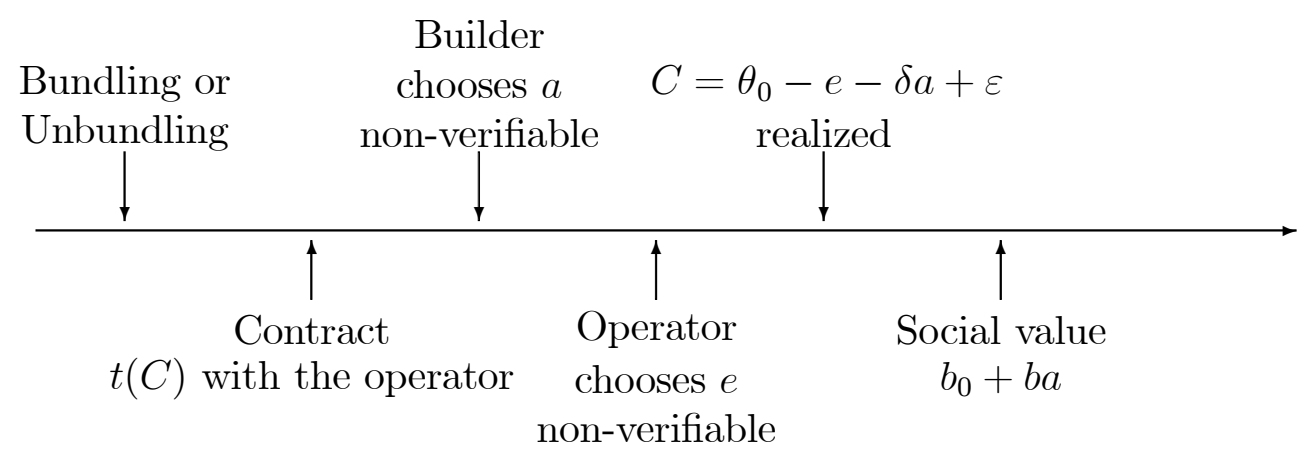

Figure 1: Timing of the game of organizational choice and contracting.

\section{Bundling or Unbundling?}

In the analysis below, we provide a rationale for relying on a PPP rather than adopting a more traditional procurement model. With such traditional contracting, $G$ first buys the infrastructure from a given builder and then selects an operator. We thus investigate whether the two tasks of respectively designing/building the assets and operating them should be bundled and performed by the same contractor (a consortium) or instead whether they should be unbundled and undertaken by two separate firms (a builder and a separate operator).

\subsection{Pure Agency Considerations: Bundling Dominates}

Unbundling: Under traditional contracting, $G$ approaches first a builder and then a separate operator. The operator receives a cost-reimbursement rule $t(C)$ net of its cost. Given our CARA-normal distribution environment, we may follow Holmström and Milgrom (1991) and restrict the analysis to the case of linear rules of the form $t(C)=\alpha-\beta C$. The case $\beta=0$ corresponds to a cost-plus contract with no incentives in cost reduction, whereas $\beta=1$ holds for a fixed-price.

To simplify presentation, we rule out the possibility that the builder obtains an incentive payment that would also depend on the realized $\operatorname{cost} C$. Instead, the builder receives a fixed payment. This contractual limitations may be justified when $G$ has a limited ability to commit to future rewards for the builder and cannot delay payment for the delivery of the infrastructure. There is also the possibility of a collusion between $G$ and the operator to exaggerate the contribution of the operator to cost-reducing activities and underestimate that of the builder. ${ }^{16}$

\footnotetext{
${ }^{16}$ We briefly discuss how the results can be extended when this assumption is relaxed in Section 3.2 below.
} 
Since he receives only a fixed payment that cannot reward him for the quality enhancing effort he may put into the design of the project, the builder does not exert any effort:

$$
a_{u}=0 .
$$

Turning now to the operator who is willing to maximize the certainty equivalent of his expected utility given the builder's own effort, his incentives constraint can be written as:

$$
e=\arg \max _{\tilde{e}} \alpha-\beta\left(\theta_{0}-\tilde{e}\right)-\frac{\tilde{e}^{2}}{2}-\frac{r \sigma^{2} \beta^{2}}{2}=\beta .
$$

An increase in the power of the incentive scheme $\beta$ raises cost-reducing effort, but as more operational risk is then transferred to $F$ the risk premium $\frac{r \sigma^{2} \beta^{2}}{2}$ increases too. Assuming that $G$ has all the bargaining power ex ante with both the builder and the operator, he can extract all their rent and just leave them indifferent between providing the service and getting their outside opportunities normalized at zero. In particular, the fee $\alpha$ is just set to cover the risk-premium that must be paid to have the risk-averse operator bearing some operational risk as requested for incentive reasons. Finally, $G$ just maximizes social welfare taking into account the incentive constraints (2) and (3) and the total benefit and cost of effort, including the risk-premium. This yields the following expression of $G$ 's problem:

$$
\max _{e} b_{0}-\theta_{0}+e-\frac{\left(1+r \sigma^{2}\right)}{2} e^{2}
$$

Immediate optimization gives the second-best value of the operating effort as:

$$
e_{u}^{S B}=\frac{1}{1+r \sigma^{2}}<1 .
$$

Because providing incentives requires the agent to bear more risk and this is socially costly, the second-best effort is less than its first-best level. As it is standard with this linear-CARA model, an increase in operational risk (making $\sigma^{2}$ larger) also means that the trade-off between insurance and incentives is tilted towards low powered incentives. ${ }^{17}$

For further references, note that social welfare under unbundling can be written as:

$$
W_{u}^{S B}=b_{0}-\theta_{0}+\frac{1}{2\left(1+r \sigma^{2}\right)} .
$$

\footnotetext{
${ }^{17}$ So far, our analysis has assumed away any cost of public funds. Suppose that any transfers from and payments to the government are weighted by a factor $1+\lambda$ where $\lambda$ is the positive cost of public funds. Then, the objective function is essentially the same as above if the social benefit of the project is deflated by the same very factor so that it becomes $\frac{b_{0}+b a}{1+\lambda}$. As a result, since $e_{u}^{S B}$ given by (4) does not depend on the social benefit of the project, the power of incentives under unbundling remains unchanged as the cost of public funds becomes positive. Without uncovering the analysis below, the benefits of bundling tasks will be de facto reduced but still positive. A second by-product of this discussion is that the issue of bundling or not tasks is independent of whether public funds are costly or not.
} 
Bundling: With this organizational form, both the building and the operational phases are in the hands of a consortium. The consortium's expected payoff is maximized when the effort levels are jointly chosen to solve:

$$
(e, a)=\arg \max _{(\tilde{e}, \tilde{a})} \quad \alpha-\beta\left(\theta_{0}-\tilde{e}-\delta \tilde{a}\right)-\frac{\tilde{a}^{2}}{2}-\frac{\tilde{e}^{2}}{2}-\frac{r \sigma^{2} \beta^{2}}{2} .
$$

Taking into account the additional non-negativity constraint $a \geq 0$, we obtain the following incentive constraints:

$$
e=\beta \text { and } a=\left\{\begin{array}{ccc}
\beta \delta & \text { if } & \delta>0 \\
0 & \text { if } & \delta \leq 0
\end{array}\right.
$$

Let us analyze the two cases in turn depending on the sign of the externality.

- Negative Externality: When $\delta \leq 0$, the consortium never chooses to perform a quality-enhancing effort because it receives no direct reward for doing so and it increases its own operating cost. This replicates exactly the same solution as in the case of unbundling.

Result 1 With a negative externality $(\delta \leq 0)$, bundling and unbundling yields the same welfare.

$$
W_{b}^{S B}=W_{u}^{S B} .
$$

There is no infrastructure quality-enhancing effort and a less than optimal cost-reducing effort.

$$
a_{b}^{S B}=a_{u}^{S B}=0 \text { and } e_{b}^{S B}=e_{u}^{S B}<e^{F B} .
$$

- Positive externality When $\delta>0$, a consortium internalizes somewhat the impact of building a high quality infrastructure because it reduces also its operating costs. Moving towards a fixed-price contract also raises incentives on infrastructure quality-enhancing; an objective which cannot be directly achieved by the public authority since that quality is hardly contractible.

Result 2 With a positive externality $(\delta>0)$, bundling strictly dominates unbundling

$$
W_{b}^{S B}>W_{u}^{S B} .
$$

The welfare gain from bundling increases with the magnitude of the externality $\delta$.

$$
\frac{\partial}{\partial \delta}\left(W_{b}^{S B}-W_{u}^{S B}\right)>0 .
$$


There is a positive infrastructure quality-enhancing effort and an increase in cost-reducing effort. PPP projects are associated with higher powered incentives and more operational risk being transferred to the private sector:

$$
a_{b}^{S B}>a_{u}^{S B}=0 \text { and } \beta_{b}^{S B}=e_{b}^{S B}>\beta_{u}^{S B}=e_{u}^{S B} .
$$

When the externality is positive, bundling induces the agent to internalize the effect of his quality-enhancing investment $a$ on the fraction of cost that he bears at the operational stage. This unambiguously raises welfare, and the stronger the positive externality, the greater the benefit of bundling.

To see why, consider the following thought experiment: Take the incentive scheme offered to the operator under unbundling, and suppose it is now given to the consortium.

The incremental welfare gain from doing so is $(b+\delta) a_{u}^{S B}-\frac{\left(a_{u}^{S B}\right)^{2}}{2}>0$ since now the consortium exerts a quality-enhancing effort $a_{u}^{S B}=\delta e_{u}^{S B}$.

Bundling shifts more risk to $F$ and brings the additional benefit of increasing its incentives to invest in asset quality. Moving from traditional procurement to PPP changes cost-reimbursement rules. Bundling and fixed-price contracts go hands in hands under PPP whereas unbundling and cost-plus contracts are more likely under traditional procurement. This is in lines with existing evidence that PPP projects are characterized by more risk transfer and thus greater risk-premia than traditional procurement.

\subsection{Robustness Check: Complete Contracting}

So far, we have ruled out the possibility that, under unbundling, the builder receives also an incentive payment that would better track the realized investment. Of course, the kind of contracts that can be signed with a builder and thus the best organizational form that arises depend on the set of contractible variables available to $G$. Let us envision the consequences of allowing more complete contracts between $G$ and $F$.

\subsubsection{Costs Incentives}

Suppose that the builder's payment is now linked to the realized level of operating costs. Doing so is attractive since these costs also reflect the quality of the infrastructure. Such contract is of the form $t_{B}(C)=\alpha_{B}-\beta_{B} C$.

Unbundling: First note that such a payment gives a positive incentive to the builder for exerting effort $a$. The builder's incentive constraint is indeed given by:

$$
a=\beta_{B} \delta \text {. }
$$


Clearly, there always exists a payment that implements the same effort pair under unbundling than under bundling. If the builder is risk-averse (with supposedly the same degree of risk-aversion as the operator) such payment has also a social cost $\frac{r \sigma^{2} \beta_{B}^{2}}{2}=\frac{r \sigma^{2} a^{2}}{2 \delta^{2}}$ which is the risk-premium needed to induce the builder's participation. Clearly, this premium increases quickly when the positive externality is small enough, i.e., when the noisy observable does not track so easily the builder's effort.

Under unbundling, the optimal quality-enhancing effort is easily obtained as trading off the efficiency gain of more effort against the risk-premium and one finds:

$$
a_{u}^{S B C}=\frac{(b+\delta) \delta^{2}}{\delta^{2}+r \sigma^{2}} .
$$

Note that this effort level is of order $\delta^{2}$ which is rather small for a weak externality. This captures the fact that contracting on cost is of little help if the builder's effort does not significantly affects costs.

Bundling: When bundling is chosen, a single incentive scheme must incentivize both dimensions of effort. The outcome is clearly the same as in Section 3.1. Note however that internalizing the externality across stages yields a first-order magnitude gains to the consortium. We can finally state:

Result 3 Assume that there is a small positive externality. Bundling strictly dominates unbundling in the more general context where complete contracts contingent on operating costs can be signed with both the builder and the operator.

The intuition is straightforward. By bundling tasks in a context where only operating costs can be contracted upon, $G$ can reduce the incentive power of the builder's costreimbursement rule, reducing thereby the risk-premium needed to induce his participation.

Bundling makes it more valuable to move towards a fixed-price cost-reimbursement rule ( $\beta$ increases) and raises both types of efforts $a$ and $e$ if the externality is positive. At the optimum, $G$ optimally trades off incentives with insurance. However, because now part of the incentive to invest in quality-enhancing effort is given through lower operating costs, there is less need to have the consortium bear so much risk.

\subsubsection{Quality Incentives}

Let us now suppose that a noisy index $q$ of the quality of the infrastructure is available:

$$
q=a+\varepsilon^{\prime}
$$

where $\varepsilon^{\prime}$ is a random variable which is assumed to be normally distributed with variance $\sigma_{\varepsilon}^{2}$ and zero mean. For simplicity we keep the same variance of noise on $q$ and the operating 
costs. This assumption is particularly relevant for the case where $q$ is in fact an earlier realization of operating costs in a context where the investment consists of complementary and renewed assets.

Now the builder's incentive scheme links his reward to the realized level of $q$. For simplicity, we assume again that such contracts are of the form $t_{B}(q)=-\alpha_{B}+\beta_{B} q$.

Unbundling: Incentive constraints for the builder and the operator are given by:

$$
a=\beta_{B} \text { and } \quad e=\beta
$$

Intuitively, although the ability to write complete contracts on a quality index improves the builder's incentives and raises the quality of the infrastructure, it does not change the operator's incentives. As a result, the second-best effort remains unchanged.

Bundling: The consortium's incentive constraint can be written as:

$$
(a, e)=\arg \max _{(\tilde{a}, \tilde{e})} \alpha+\beta_{B} \tilde{a}-\beta\left(\theta_{0}-\tilde{e}\right)-\frac{\tilde{a}^{2}}{2}-\frac{\tilde{e}^{2}}{2}-\frac{r \sigma^{2} \beta_{B}^{2}}{2}-\frac{r \sigma^{2} \beta^{2}}{2}+\beta \delta a=\left(\beta_{B}+\beta \delta, \beta\right) .
$$

By making F's payment depend on the quality index, $G$ gives to $F$ more incentives to invest in asset quality. As $F$ is risk-averse such contingent payment raises the risk premium by $\frac{r \sigma^{2} \beta_{B}^{2}}{2}$. However, under bundling and a positive externality, part of the risk necessary to induce incentives in quality-enhancing can be obtained by making the cost reimbursement rule more powerful without undermining operational costs. This reduces the risk-premium related to the design activity and improves welfare.

Result 4 Bundling strictly dominates unbundling when complete contracts on both operating costs and a quality index are feasible and the externality is positive.

Even if better information over asset quality eases the agency problem under unbundling, bundling remains the preferred option whenever the auditing of infrastructure quality is imperfect.

\subsection{Residual Value and Ownership}

Taken in tandem, Results 1 and 2 just tell us that bundling at worst weakly dominates unbundling. With a positive externality, bundling raises welfare as it eases the moral hazard problem. With a negative externality and under unbundling, investment $a$ is already at a minimum, the builder having no incentives to invest. Bundling is of no value.

If we were taking only the "agency route" as a justification of PPPs, the results of this simple model would be a little bit too weak: PPPs should always be weakly preferred. 
The important issue is thus to find conditions under which unbundling, viewed as a more traditional form of public procurement, may be strictly optimal. ${ }^{18}$ To do so we will now identify PPP as an organizational form where there is bundling of design and operation phases but also private ownership of the assets over the length of the contract. Traditional contracting corresponds instead to the case where $G$ buys an asset built (and thus initially owned) by the private sector and operates it through a second firm be it private or public.

Ownership of the infrastructure matters to the extent that assets have some residual value for the owner at the end of the contract. Ownership entitles the owner with the market value of these assets. Enjoying this residual value provides incentives to invest in asset quality so that ownership is also a substitute for more complete contracts. Of course, that residual value will depend on assets specificity. Indeed, facilities for the provision of public services are distinguished into two categories: (i) generic facilities, such as leisure centers, office accommodation, general IT systems and land use; and (ii) specific facilities, such as hospitals, prisons and schools. In the case of generic facilities, there is demand from users other than the government, so that the public and private residual value do not differ significantly.

To model these issues, let $s a$, with $s>0$, denote the value of the assets at the end of the contract when these assets are used by the government for public service provision, and let $\gamma s a$, with $\gamma<1$, denote the corresponding value for private use. Consistently with much of the incomplete contracts literature, ${ }^{19}$ the residual value of these assets cannot be specified ex ante in a contract although it is ex post observable once realized and can be bargained upon at that date. $\gamma$ captures the degree of asset specificity, with $\gamma$ being higher the less specific is the facility. Since $\gamma<1$ it is always optimal that the facility be owned by $G$ at the end of the contract. That the asset returns to $G$ at the end of the contract is indeed one of the main features that distinguishes PPP from privatization.

As a benchmark, note that the first-best level of $a$ now solves

$$
a^{F B}=s+b+\delta
$$

\subsubsection{Public Ownership}

Suppose that $G$ owns the asset throughout the contract. Since $a$ is not contractible and since no sale of the facility occurs once the contract expires, there is no way giving any incentives to the firm. Whether bundling or unbundling is chosen, efforts and welfare with public ownership remains the same as before in both cases. Public ownership has

\footnotetext{
${ }^{18}$ Actually, one can show that in the context of Section 3.2.2 unbundling dominates for a negative externality.

${ }^{19}$ Hart (1995).
} 
no impact on incentives. Whether bundling strictly dominates depends on the sign of the externality as in Section 3.1.

\subsubsection{Private Ownership}

Suppose assets are privately owned. At the end of the contract, efficiency requires to transfer ownership to $G$. Assuming that, ex post, the price $p^{*}$ at which ownership is transferred results from Nash bargaining with equal bargaining power between $G$ and $F$ :

$$
p^{*}=\arg \max _{p}(s a-p)(p-\gamma s a)=\frac{(1+\gamma)}{2} s a .
$$

This yields to the private owner a net benefit $\frac{(1-\gamma)}{2} s a$ which is increasing in $a$ and boosts his incentives to enhance the quality of the assets if he is a builder. ${ }^{20}$

Note that the owner's incentives to invest is greater when the asset is less specific. Indeed, asset specificity decreases the status quo payoff if ownership is not transferred to the public sector at the end of the contract. This exacerbates the hold-up problem that occurs through ex post bargaining and dampens the private owner's incentives.

- Private ownership and unbundling: With unbundling and ownership by the builder, the builder's incentive constraint can be written as:

$$
a_{u}^{p r}=\frac{(1-\gamma)}{2} s
$$

The operator's effort and optimal incentive scheme remain the same as in Section 3.1:

$$
e_{u}^{p r}=e_{u}^{S B}
$$

- Private ownership and bundling: Ownership has still some value with bundling. The consortium's expected payoff is maximized for effort levels that solve:

$$
(a, e)=\arg \max _{(\tilde{e}, \tilde{a})} \frac{(1-\gamma)}{2} s \tilde{a}+\alpha-\beta\left(\theta_{0}-\tilde{e}-\delta \tilde{a}\right)-\frac{\tilde{a}^{2}}{2}-\frac{\tilde{e}^{2}}{2}=\left(\beta \delta+\frac{(1-\gamma)}{2} s, \beta\right)
$$

where $s$ is large enough to insure a positive quality-enhancing effort even with a negative externality.

Comparing public ownership with private ownership, we immediately obtain:

Result 5 Private ownership always dominates public ownership. The gain from private ownership is non-increasing in the level of asset specificity.

\footnotetext{
${ }^{20}$ It should be clear that under, unbundling, ownership by the builder is preferable to ownership by the operator since the operator has no control on quality-enhancing effort.
} 
Comparing now PPPs and traditional procurement, we get:

Result 6 PPPs, i.e., Private ownership and bundling, strictly dominates traditional contracting, i.e., private ownership and unbundling, if and only if the externality between the design and the operation phases is positive:

$$
W_{b}^{p r}>W_{u}^{p r} \text { if and only if } \delta>0 .
$$

Efforts are greater under bundling if and only if the externality is positive.

$$
a_{b}^{p r}>a_{u}^{p r}=\frac{(1-\gamma)}{2} s \text { and } e_{b}^{p r}>e_{u}^{p r} \text { if and only if } \delta>0 .
$$

Compared to the case of public ownership, bundling leads now to strictly lower efforts than unbundling under private ownership if the externality is negative. Ownership of the asset gives to the builder positive incentives to invest in asset quality. These incentives are then depressed if the builder is induced to internalize the negative externality that asset quality exerts on operational cost.

Giving ownership of the infrastructure to the builder reduces the hold-up problem and boosts quality-enhancing effort $a$ (whatever the sign of the externality). ${ }^{21}$ The builder, when an owner, appropriates part of the surplus from enhancing quality of the infrastructure and the more so the greater the asset specificity (i.e., the higher is $\gamma$ ). Since the value of improving quality is not risky, there is no risk premium associated to private ownership and private ownership is always optimal. Then private ownership is more beneficial for generic facilities, (where $\gamma$ is high), such as leisure centers and housing, than for specific facilities such as hospitals, prisons or schools. However, since the contractor never fully internalizes the positive effect on social benefit $b$, underinvestment in quality always follows. When a higher building quality raises operational cost, bundling is suboptimal as internalization of the externality would depress investment further.

\subsection{Related Literature and Applications}

Literature : Our model has merged two strands of the literature on PPPs which have both emphasized the multitask nature of the procurement problem when building and managing assets are at stake. Hart (2003) built on Hart, Shleifer and Vishny (1997) provided a model where the sole source of incentives is ownership. A builder can perform

\footnotetext{
${ }^{21}$ However, results may change if $a$ has a negative impact on the market value of the asset, though it still increases the value of the asset when used for public purposes. This is likely to occur for facilities for which the design is very specific to the delivery of the public service. See Rajan and Zingales (1998).
} 
two kinds of investment (productive and improductive) which may both reduce operating costs, although only the productive investment raises also the benefit of providing the service. Under traditional procurement, the builder cannot internalize the impact of his effort neither on benefits nor on costs and, as a result, implements too little of the productive investment but the right amount of the unproductive one. Under PPP, the builder internalizes partly the impact of his productive investment whereas he also exerts too much of the unproductive one. Turning to the case where ownership concerns a public good and still using the property rights approach, Besley and Ghatak (2001) showed that ownership should lie in the hands of that player with the highest valuation for the public good, explaining thereby that non-governmental organizations may be given property rights. Finally, Francesconi and Muthoo (2006) considered the case of impure public goods and, in a model where each party may have control rights on a subset of decisions, showed that shared authority can be optimal in case the parties' investments are comparable. On similar issues, see also King and Pitchford (2001).

Bennett and Iossa (2006) studied the desirability of bundling project phases and of giving ownership to the investor. In their model innovations are non-contractible ex ante but verifiable ex post. Ownership of the asset gives control right to the owner to decide whether to implement quality enhancing or cost-reducing innovation proposed by the investor. It is shown that the hold-up problem is less severe under PPP, compared with traditional procurement, when there is a positive externality between the building and managing stages. With a negative externality the opposite can hold. Further public ownership acts as a commitment for the government to renegotiate and share with the investor the surplus from the implementation of the innovation. Private ownership is however optimal for generic facilities with high residual value.

Martimort and Pouyet (2008) built a model where both the quality of the infrastructure and operating costs are contractible. Agency costs are lower under a PPP when there is a positive externality between building and managing assets compared with traditional procurement. Granting ownership is an imperfect way of aligning incentives but, to a large extent, the important issue is not who owns the asset but instead whether tasks are bundled or not. That insight is developed in various extensions of their basic model allowing for risk-sharing as a motive for forming consortia, or political economy. In this respect, a common theme of their model and ours is that PPP comes with higher powered incentives which are prone to collusion and capture of public officials. When those institutional costs are taken into account, relying on PPP becomes less attractive.

An alternative, complete-contract, approach to PFI was taken by Bentz, Grout and Halonen (2001). They showed that the government will wish to buy services (as in PFI) rather than facilities (as in traditional procurement) if the building and service delivery costs are low. 
Applications: Our results suggest that PPPs are likely to deliver efficiency gains when a whole-life cost approach to the project has the potential to yield significant cost savings and when risk is effectively transferred to the private operator. Transfer of design, construction and operating risk to the contractor provides incentives for within cost delivery of the infrastructure and in general provision of the service. A report commissioned by the Treasury Taskforce (Arthur Andersen and LSE, 2000) estimated saving on a sample of PFI projects equal to $17 \%$, compared to traditional procurement. ${ }^{22}$ Interestingly, significant cost savings were realized in the prison sector. The National Audit Office (2003a) reported that innovative design solutions helped to reduce the level of staffing needed to ensure security and this resulted in an overall cost reduction by approximately $30 \% .80 \%$ of a prison's running costs are indeed staff costs. Conclusive evidence is however still to be found. Blanc-Brude, Goldsmith and Välilä (2006) studied a sample of road projects financed by the EIB between 1990 and 2005 in all EU-15 countries plus Norway. They found that ex ante construction costs (i.e., costs before construction actually starts) are some $20 \%$ higher for PPP roads than for traditionally procured roads. The data does not reveal the actual (ex post) cost of the projects and thus whether risk transfer under PPP was effective in containing cost overruns.

Our results also suggest that, when a higher asset quality increases social benefit but it has a negative impact on whole-life cost, the scope for PPP is reduced if not eliminated. Evidence of negative externalities is more difficult to find. However, a report by the Audit Commission (see PPP Focus, Education 2, 2004) noted that the quality of many early PFI school buildings was disappointing. Schools had few windows, poor acoustic and air quality, compared to traditionally procured schools. School quality has a direct positive impact on pupil behavior and educational achievement and a higher number of windows which provide daylight is more costly to maintain because of the risk of school vandalism. Local Education Authorities now anticipate this problem and include more detailed output specifications in the contract. As a result the quality of school buildings has improved.

Our results also shed some lights on the current approach to facility ownership. Under PPP, ownership of the infrastructure during the contract period belongs to the consortium, but the ownership once the contract expires varies depending on the circumstances. Assets tend to revert to the public sector either when there is no practical alternative use for them or when the asset is needed to provide a continuing service after contract end (for example, schools, prisons and hospitals). For generic facilities with an alternative use outside the public sector and no clear long-term public sector need, ownership is retained by the private sector.

\footnotetext{
${ }^{22}$ However, Pollock and Vickers (2000) question the Andersen report and argue that once outliers are excluded from the calculations the average saving is 6 per cent.
} 
We have focused on the benefits of bundling that may come from inducing the contractor to take a long-term approach to the project. However, bundling also brings other effects, not discussed above. First, PPP projects are characterized by a longer procurement process and by higher costs of bidding than traditional procurement. Albeit with differences between sectors, it has been estimated that PPP tendering periods last an average of 34 months $(\mathrm{NAO}, 2007)$ and that procurement costs can reach $5-10 \%$ of the capital cost of a project (Yescombe, 2007). These transaction costs are also to a large extent independent of the size of a project, which suffices to make PPP unsuitable for low capital value projects. The HM Treasury (2006) currently considers PFI projects for less than $£ 20$ m as poor value for money.

Second, bundling of different phases of the project increases project complexity and limits participation of small construction companies that do not have the necessary financial resources to sustain the costs and risks of bidding for PPP contracts. Albeit with differences across sectors, in the UK there is an average of 4 bidders per PPP contract. This is problematic as collusion among bidders is certainly more likely if the number of participants is small.

In our basic model we have talked about only two tasks: building and operation. In practice, the realization of a project comprises a wider variety of tasks. Services in the operational stage for example include 'soft' facility-management services (e.g. cleaning, catering, security) and 'hard' facility-management services (e.g. routine and/or life-cycle maintenance of buildings and equipment). The arguments set up in this section apply to hard services where asset quality matters but less so to soft services where asset quality plays a limited role. Whether to include soft services in PPP contracts should follow other considerations. On the one hand, their inclusion has the advantage of creating a single point of responsibility within the private sector in charge of final service provision. On the other hand, unbundling helps to employ short-term contracts for soft services and thus to benefit from more competitive pressure. Separate tendering for soft services also favors the participation of small firms. There are no uniform experiences across countries regarding service unbundling and the HM Treasury (2006) currently advises against their inclusion.

\section{Demand Risk}

\subsection{Optimal Risk Allocation}

A critical aspect of any PPP contract is the allocation of demand risk between the government and the contractor. The means through which demand risk is allocated is the 
payment mechanism. Broadly speaking there are three main payment mechanisms, depending on whether the payment is based on (i) user charges, (ii) usage, or on (iii) availability. ${ }^{23}$ In a payment mechanism solely based on user charges, the contractor receives its revenues directly through charges on the end users of the infrastructure facility and bears all demand risk. Instead, in a payment mechanism based on usage, the government collects user charges and then makes unitary payments to the contractor. The allocation of demand risk depends on the relationship between the payment and the actual usage level. In a payment mechanism based on availability, the government rewards the contractor for making the service available but the payment is independent of the service actual usage; the government retains all demand risk. In many schemes, the payment to the contractor comprises a combination of the above payment schemes.

To see the factors that affect the optimal allocation of demand risk and the choice of the payment mechanism, assume that consumers have an inelastic demand for the service up to some price level $p_{0}$ which is given by:

$$
D(p)= \begin{cases}d_{0}+a+\eta & \text { if } p \leq p_{0} \\ 0 & p>p_{0}\end{cases}
$$

The random variable $\eta$ is normally distributed, with zero mean and variance $\sigma^{2}$. $a$ is a demand-enhancing effort whose disutility counted in monetary terms is still $\frac{a^{2}}{2}$.

The firm can extract all the consumer's surplus by means of a fixed-fee (for instance a toll in the case of highways). It gets thereby the expected revenue:

$$
E_{\eta}(R)=p_{0} E_{\eta}\left(\max \left\{d_{0}+a+\eta, 0\right\}\right) \approx p_{0}\left(d_{0}+a\right)
$$

where the approximation above holds when $\sigma^{2}$ is small enough compared to the base level of demand $d_{0}$.

For simplicity, we assume away any incentive problem on the cost side and zero marginal costs of providing the services. With those assumptions, a linear payment mechanism is in full generality a scheme of the form $t(R)=\alpha+\beta R$. The fee $\alpha$ is a fixed payment to the firm (or subsidy) paid irrespectively of the revenue generated. The coefficient $\beta$ is meant for the share of those revenues which are left to the firm. The share $1-\beta$ being left to the government. To fix ideas, a payment mechanism solely based on user charges corresponds to the case $\alpha=0$ and $\beta=1$ so that the contractor bears all demand risk and receives no insurance. In a payment mechanism based on availability, $\alpha>0$ and $\beta=0$ so that the contractor's reward is fixed and the government retains all demand risk.

\footnotetext{
${ }^{23}$ For a more in depth discussion see Iossa, Spagnolo and Vellez (2007). An interesting issue that we do not address concerns political accountability under various contractual forms. In this respect, Athias (2008) compares the performance of concession contracts and availability contracts in terms of their impacts on the incentives of public authorities to respond to customers needs.
} 
The contractor maximizes the certainty equivalent of his expected utility and his incentive constraint can be written as:

$$
a=\arg \max _{\tilde{a}} \alpha+\beta p_{0}\left(d_{0}+\tilde{a}\right)-\frac{\tilde{a}^{2}}{2}-\frac{r \sigma^{2} \beta^{2} p_{0}^{2}}{2}=\beta p_{0} .
$$

From this characterization of the incentive constraint, we get:

Result 7 The optimal payment mechanism comes closer to be based on user charges only when risk-aversion and demand risk are small (high-powered incentives). Instead, the payment mechanism moves towards being based on availability only when risk-aversion and demand uncertainty are large (low-powered incentives).

Transferring demand risk to the contractor gives it incentives to boost demand and raise consumer surplus but it costs the government a higher risk-premium. The optimal payment mechanism trades off incentives and insurance. Further, if we let $\lambda$ be a scale parameter affecting the impact of $a$ on demand (namely, we have now $D(p)=d_{0}+\lambda a+\eta$ ), we easily find that both $\beta^{S B}$ and $a^{S B}$ raise with $\lambda$. That is, for PPPs in sectors such as transport, where demand levels are affected by the contractor's action, demand risk should be borne mainly by the contractor. For PPPs in sectors such as prisons, or schools, where usage mainly reflects government policy in the sector, demand risk should be borne mainly by the government.

Remark 1: Investment. Suppose that the firm must cover an investment of size $I$ with the revenue of the service. The investment is realized when the fee is increased by the value of the investment:

$$
\alpha^{S B^{\prime}}=I+\alpha^{S B} .
$$

When fees are available, there is no problem in passing the cost of investment to the government, i.e., to taxpayers. We come back in Section 5 below on the conditions for financing investments when such fees are no longer available.

\subsection{Private Finance Initiative}

So far we have implicitly focused on conventional PPPs, under which the public sector pays the private sector party for the service that it will provide using the infrastructure. Providers of PPP hospitals, schools and prisons receive their funding in this manner. PPP arrangements however are often characterized by the private sector financing a substantial part, or all of, the project (the "F" in the DBFO model). With financially free-standing projects, the private provider then recoups its initial investment through charges to final users. Here, the public sector involvement is limited to facilitating the project and the 
PPP is very similar to a concession contract. In this section we briefly study the case of financially free standing projects.

Consistently with the PFI practices, we consider a setting where there are no direct subsidies from the government to the firm and all revenues are left to the firm over the duration of the contract, i.e., $\alpha=0$ and $\beta=1$. The firm must cover its initial investment $I$ from the revenues it withdraws from charging user fees over the length $T$ of the contract. After date $T$, the PPP goes back under public ownership and the access toll is set at zero.

To complete our modeling, assume that the shocks on the level of demand are drawn once for all whereas the cost of effort is sunk and borne once for all beforehand. With these assumptions in mind, intertemporal income smoothing for the firm leads to rewrite the firm's discounted stream of certainty-equivalent payoffs when choosing effort $a$ and making the investment $I$ as:

$$
\begin{gathered}
E_{\eta}\left(u\left(-I-\frac{a^{2}}{2}+\int_{0}^{T} p_{0}\left(d_{0}+a+\eta\right) \exp (-\rho t) d t\right)\right) \\
=u\left(-I-\frac{a^{2}}{2}+(1-\exp (-\rho T)) p_{0}\left(d_{0}+a\right)-\frac{r \sigma^{2}}{2}(1-\exp (-\rho T))^{2} p_{0}^{2}\right)
\end{gathered}
$$

where $\rho$ is the interest rate in the economy.

This immediately leads to the following moral hazard constraint:

$$
a=(1-\exp (-\rho T)) p_{0} .
$$

Clearly, the longer the duration of the contract $T$, the greater the firm's effort since its benefits accrues over a longer period. Note that the term $1-\exp (-\rho T)$ plays the same role as $\beta$ in formula (13) above. Indeed, instead of directly sharing the revenue with the firm in each period, the government let the firm enjoy all revenue but for a finite duration.

Also, undertaking the investment is optimal when:

$$
(1-\exp (-\rho T)) p_{0}\left(d_{0}+a\right)-\frac{a^{2}}{2}-\frac{r \sigma^{2}}{2}(1-\exp (-\rho T))^{2} p_{0}^{2} \geq I .
$$

This condition plays the role of a break-even constraint in standard Ramsey analysis when the government cannot use lump-sum payment to finance investment directly. Accordingly, we will now on consider that $G$ is a social welfare maximizer giving equal weight to consumers and the firm in his objective function.

Suppose first that the investment constraint (15) is slack. The second-best effort level is then easily obtained as:

$$
a^{S B}=\frac{p_{0}}{1+r \sigma^{2}}=p_{0}\left(1-\exp \left(-\rho T^{S B}\right)\right) .
$$


From which, we derive the optimal unconstrained length of the franchise as:

$$
T^{S B}=\frac{1}{\rho} \ln \left[1+\frac{1}{r \sigma^{2}}\right] .
$$

More demand risk and a greater degree of risk-aversion both call for reducing the incentive power and for more insurance which is obtained by reducing the length of the contract.

However, with financially free-standing projects the length of the contract must be chosen so as to guarantee that the stream of expected revenues coming from user charges is sufficient to cover the firm's investment as well as the risk-premium.

Suppose that $T^{S B}$ is such that (15) does not hold. The length of the contract has to be modified to ensure that the firm breaks even. We get:

Result 8 Assume that the investment constraint is binding. Franchise lengths are shorter in more uncertain environments ( $\sigma^{2}$ greater), when consumers' willingness to pay is greater ( $p_{0}$ greater), when investment is lower (I lower).

Literature: Our framework is related to Engel, Fischer and Galetovic (2001) who study optimal contract length in concession contracts, but in their paper there is no moral hazard. Engel, Fischer and Galetovic (2006) study the rationale for private finance in PPPs. ${ }^{24}$ They showed that private finance cannot be a means to save on distortionary taxation. Any additional $\$ 1$ invested by the contractor saves society distortionary taxes but the concessionaire must be compensated for the additional investment through a longer contract term and this costs society future distortionary taxes equal to the initial tax saving. Further, when demand risk is substantial, the optimal contract is characterized by a minimum revenue guarantee and a cap on the firm's revenues.

Applications: Our results suggest that when demand is affected by the contractor's effort, transferring demand risk to the contractor helps incentives. In practice, with financially free-standing PPP projects, the payment mechanism is based on user charges and demand revenue risk lies with the contractor who is then residual claimant for demand changes. With conventional PPP projects, such as hospitals, schools and prisons, the contractor's effort has little impact on demand levels as government policies determine most of demand changes. The payment mechanism is then based on usage with the government bearing demand risk. In our model, it is immediate that if $D$ is independent of $a$ then it is suboptimal to transfer demand risk to the contractor.

The private finance aspect of PPPs has allowed the public sector to finance the construction of infrastructure "off the balance sheet" and to accelerate delivery of projects

\footnotetext{
${ }^{24}$ See also the informal discussion in De Bettignies and Ross (2004).
} 
(see IPPR, 2001). The accounting treatment of this stream of payments can vary and it can often make the government budget look healthier than what it is, thereby undervaluing the cost of PPP financed infrastructure. This not only biases decisions in favor of PPPs as opposed to more traditional procurement arrangements but it can make PPPs a means to unduly transfer costs from current to future generations. ${ }^{25}$

There is no economic justification for PPPs being promoted for allowing investment off the balance sheet. In order to ensure homogeneity across member states and limit accounting tricks made to comply with the rules of the Stability and Growth Pact, Eurostat has recently made a decision (news release 18/2004) on the accounting of PPPs, which has the power to clarify and make the process of accounting true PPPs more transparent. However, the temptation to adopt PPPs as a tool to window dress budget deficits has not been fully removed. ${ }^{26}$

\section{$5 \quad$ Bundling Financing and Operating Tasks}

The relationship between investment and their financing is particularly critical for infrastructures. On the one hand, PPPs projects have recently attracted much attention among financiers because those investments are known as providing stable returns which, to a large extent, are uncorrelated with the market. On the other hand, an often heard benefit of PPPs is that they might bring in the expertise of outside financiers in evaluating risks. In this respect, bundling the task of looking for outside finance (be it through outside equity or debt) and operating assets could improve on the more traditional mode of procurement where the cost of investment is paid through taxation and investment is not backed up by such level of expertise within the public sphere.

To address those issues, we build on the basic moral hazard model highlighted in Section 2. To focus on the benefit of bundling operation and financing, we assume $b=0$ so that, there are no social benefit of designing a better infrastructure.

To model the transaction costs that might still arise when the operator looks for outside finance, we assume now that financiers have expertise to get access to some informative signal $y$ on the contractor's effort:

$$
y=e+\eta
$$

where $\eta$ is a random variable which is assumed to be normally distributed with variance

\footnotetext{
${ }^{25}$ See Maskin and Tirole (2007) for a study on optimal public accounting rules when the official's choice among projects is biased by ideology or social ties or because of pandering to special interests.

${ }^{26}$ According to the 2004 Eurostat's decision assets involved in a PPP should be classified as nongovernment assets, and therefore recorded off balance sheet for government, if the private partner bears the construction risk and at least one of either the availability risk or the demand risk. Otherwise, the assets should be classified as government assets.
} 
$\sigma_{\eta}^{2}$ and zero mean. Of course, using such informative signal may be quite useful as we already know from the Informativeness Principle. ${ }^{27}$

We investigate in turn the case of public finance where the investment is levied by taxation and the case of outside private finance.

Public finance: Consider first the case where the government itself provides funds to cover an investment outlay of size $I$. The government does not observe the informative signal $y$ and implements only the second-best effort $e_{u}^{S B}$.

Outside finance: Consider now the case where the operator has full control over his access to the financial market on top of control over operations. To fix ideas, suppose that the operator still receives a linear scheme $t(C)=\alpha-\beta C$ from the government. Given the contract that is assumed observable by outside financiers, the contractor and those financiers agree on how to share the associated remaining risk.

Let us thus denote by $\gamma$ the fraction of the firm's reward that is kept by the operator. Because outside financiers can condition how much repayment they request from the firm on the extra signal $y$ that they observe, a general linear scheme for repayment can be written as:

$$
z(C, y)=E+(1-\gamma)(\alpha-\beta C)-\xi y
$$

where the term $\xi y(\xi>0)$ is a bonus in case the signal on the firm's effort is high enough. Since financiers are competitive, the fixed-payment $E$ is the price of equity they hold in the project net of the investment cost $I$.

Given those schemes, we can rewrite the operator's incentive constraint as:

$$
e=\arg \max _{\tilde{e}}-E+\gamma\left(\alpha-\beta\left(\theta_{0}-\tilde{e}\right)\right)+\delta \tilde{e}-\frac{\tilde{e}^{2}}{2}-\frac{r \sigma^{2} \gamma^{2} \beta^{2}}{2}-\frac{r \sigma_{\eta}^{2} \xi^{2}}{2}=\beta \gamma+\xi .
$$

This incentive constraint highlights two important features. First, only a fraction of the incentive power of the government's scheme ends up being useful to foster effort because of subsequent risk-sharing between the firm and financiers. Second, financiers can improve incentives by conditioning the firm's repayment on the informative signal they get on its effort.

Going backwards, let us turn now to the design of the overall repayment scheme given the transfer scheme with the government. Because financiers are competitive, this repayment maximizes the certainty equivalent of the operator's payoff taking into account the moral hazard incentive constraint (19):

$$
\left.(\xi, \gamma)=\arg \max _{(\tilde{e}, \tilde{\delta}, \tilde{\gamma})} \alpha-\beta\left(\theta_{0}-\tilde{e}\right)\right)-\frac{\tilde{e}^{2}}{2}-\frac{r \sigma^{2} \tilde{\gamma}^{2} \beta^{2}}{2}-\frac{r \sigma_{\eta}^{2} \tilde{\xi}^{2}}{2}
$$

${ }^{27}$ Holmström (1979). 


$$
\text { subject to } \tilde{e}=\beta \tilde{\gamma}+\tilde{\xi} \text {. }
$$

The optimal repayment scheme designed by financiers is straightforward. The share of risk left to the operator is independent of the government's scheme. The firm gets positive bonus in case $y$ is good news on the firm's effort:

$$
\gamma=\frac{1}{1+\frac{\sigma^{2}}{\sigma_{\eta}^{2}}\left(1+r \sigma_{\eta}^{2}\right)} \text { and } \xi=\gamma \beta \frac{\sigma^{2}}{\sigma_{\eta}^{2}} .
$$

This corresponds to a risk-premium borne by the operator which is worth $\frac{r \sigma^{2} \beta^{2}\left(1+\frac{\sigma^{2}}{\sigma_{\eta}^{2}}\right)}{2\left(1+\frac{\sigma^{2}}{\sigma_{\eta}^{2}}\left(1+r \sigma_{\eta}^{2}\right)\right)^{2}}$.

Finally, the effort level implemented by the operator when one compounds the impact of government's and the financiers' contracts can be written as:

$$
e=\frac{\left(\sigma_{\eta}^{2}+\sigma^{2}\right)}{\sigma_{\eta}^{2}\left(1+r \sigma^{2}\right)+\sigma^{2}} \beta .
$$

This condition can be viewed as the incentive constraint that applies to the coalition between the operator and its financiers.

Notice that this effort level converges towards $\beta$ when $\sigma_{\eta}^{2}$ converges towards zero. When the financiers have a very informative signal on the firm's effort, there is no further dilution of incentives within their coalitional agreement: Effort is efficiently set within the firm/financiers coalition. Instead, when $\sigma_{\eta}^{2}$ converges towards infinity, the effort level converges towards $\frac{\beta}{1+r \sigma^{2}}$ which captures the fact that part of the incentives given by the government are dissipated through further risk-sharing with financiers.

Comparing with the results under public finance, we observe that moving towards private finance unambiguously raises incentives and moves the outcome closer to the firstbest.

Result 9 Bundling private finance and operation is optimal when outside financiers have access to some informative signal on the operator's effort level. The power of incentives unambiguously raises and aggregate welfare improves with respect to public finance.

The intuition for this result is straightforward. Relying on outside finance makes the operator less risk-averse, even though outside finance may exacerbate moral hazard by introducing further risk-sharing. The point is that, as the financial contract is made under a better information structure, the extra round of contracting with financiers has more benefits in terms of improved incentives than costs in terms of modified risk-sharing. Intuitively, everything happens as if the government itself was enjoying the financiers' expertise. 
Remark 2: Market power on the financiers' side. Suppose now that financiers have specialized in analyzing infrastructure risk. First, such financiers are likely to have market power when designing financial contracts with operators. Second, those financiers might not be fully diversified if a large part of their financial activities come from the infrastructure sector. It is unlikely that, in such environment, the government can recoup all benefits from the financiers' expertise. A double-marginalization problem might occur with both the government and financiers willing to reduce the firm's effort. There will be a trade-off between the benefits of the financiers' expertise and the extra distortions that financial contracts might bring.

\section{Uncertainty, Flexibility and the Costs of PPPs}

PPP agreements are output-based in the sense that the public-sector party specifies basic capacity and quality standards (such as heating and lighting levels, quality of cleaning and availability of rooms) but the private-sector party assumes responsibility over how to meet the output specified. PPP agreements also develop along a long-time horizon, typically 20-35 years. Both these features imply that the provisions set in the initial contract are likely to become obsolete during the life of the contract. The need for flexibility and adaptation of the contractual relationship is then far greater than in a more traditional types of procurement where provisions are input-based and contracts are short-term. ${ }^{28}$

When the factors that affect the suitability of the initial contractual clauses are anticipated, they can be regulated by the initial contract (e.g. changes in capacity). Other possible changes, however, may be unexpected and hard to specify in advance. Changes in society preferences, such as desirable standards for educational, clinical and prison services, are typically hard to anticipate. Contract flexibility is then key for PPP agreements in fast-moving sectors such as the health sector and the IT sector where preferences and/or technology change quickly.

When the original output specifications become obsolete, the contractual agreement can be modified by the mutual consent of the parties. Flexibility may then be achievable through well-designed "change the mechanism-clauses" that regulate the possibility of renegotiation of contract terms. However, contract renegotiation typically occurs in a bilateral "lock-in" situation rather than in the multilateral competitive one as under original contract drafting and awarding. The risk is twofold: The contractor can exploit its now strong bargaining position or the government can expropriate the contractor of its past investment. Thus both when renegotiation occurs and new contract terms are

\footnotetext{
${ }^{28}$ The literature on contracts and adaptation is rather thin. Arve (2007) analyzes the incentives to build-up investment over time as more of the initial uncertainty on demand gets realized both under full and limited commitment.
} 
drafted and when the contract is rigid and no change occurs, PPP might deal inefficiently with uncertainty on future demand. This induces a cost of PPPs that we now study. For simplicity we focus on the case where the contract fails to adapt to uncertainty on future demand and renegotiation does not occur.

Let us come back on the basic model but assume that the inelastic demand for the services can be written as:

$$
C=\theta_{0}-\gamma e-\delta a+\varepsilon
$$

where $\gamma$ is a positive random variable with $E_{\gamma}(\gamma)=1$ and we assume a positive externality $\delta>0$.

Had $\gamma$ been common knowledge at the time of contracting, our previous result would go through and bundling design and operation would dominate strictly unbundling.

Suppose now that the bundling contract (viewed as a PPP) is offered before $\gamma$ is realized and cannot be made contingent on that parameter, assumed unverifiable. ${ }^{29}$ In other words, $G$ ties his hands with such a contract and loses any flexibility. Alternatively consider unbundling tasks. Contracting with the operator might be delayed up to the point where $\gamma$ becomes verifiable. Of course there is no quality-enhancing investment but the operator's incentive scheme can be tailored to the particular realization of $\gamma$. This captures the value of information that comes with unbundling. We have:

Result 10 Unbundling dominates bundling for small positive externality in the case of uncertainty.

The point is that unbundling tasks allows to enjoy the value of information on $\gamma$ and that it is not possible under bundling. This points at the cost of PPPs in very uncertain environments. A reinterpretation of our framework also suggests that long-term contracts are unsuitable in uncertain environments. ${ }^{30}$ Consider the framework of Section 7.1 but now let period- 2 cost be given by

$$
C_{2}=\theta_{0}-\gamma e_{2}-\delta a+\varepsilon_{2}
$$

Assume that $\gamma$ is realized during period 1 and that a two-period contract covering both periods 1 and 2 cannot be made contingent on the realized $\gamma$. It is easy to show that with a low externality ( $\delta$ small) a one-period contract becomes preferable to a contract covering both periods. This is because when the externality is small, the loss from not internalizing

\footnotetext{
${ }^{29} \mathrm{We}$ are assuming also that it is not possible to write a revelation mechanism that would make the cost-sharing scheme contingent on any announcement that the firm and the government could be making when informed about $\gamma$. In other words, we are considering here an incomplete contracts environment.

${ }^{30}$ However, under certain conditions, short-term contracts perform as well as long-term contracts (see e.g. Rey and Salanie (1996)).
} 
period 2 cost at the time of choosing asset quality $a$ is small and the one-period contract allows to enjoy the value of information on $\gamma$ whilst the two-period contract cannot.

Literature: Bajari and Tadelis (2001) discussed the cost of renegotiating design under fixed-price and cost-plus contracts. When the firm has private information on the cost of the new design, cost-plus contracts are cheaper to renegotiate than fixed-price ones. In this respect, sectors where changes in demand are highly expected may be better procured through cost-plus contracts in spite of fixed-price contracts being preferable for inducing the agent's cost reducing effort.

Our results emphasize that the long-term nature of PPP contracts favors incentives for cost reducing effort but it has a cost in terms of reduced flexibility. The trade-off between incentives and flexibility was recently examined by Ellman (2006) though his focus was on investment by the government rather than by the firm. He showed that a longer contract length helps to protect the contractor from his investment being expropriated by the government but it reduces the incentives of the government to discover new service innovations since changes are costly to renegotiate.

Applications : Our results point to the unsuitability of PPP for fast-moving sectors. This is in line with empirical evidence. Several recent reports on PPP contracting highlight the cost of changes in user needs that - in the presence of rigid contracts - have sometimes triggered very costly renegotiation (see e.g. HM Treasury 2006). In the UK it was reported that changes occurred during negotiations with the contractors for $33 \%$ of Central Government Departments PFI projects signed between 2004 and 2006. The changes amounted to a value of over $£ 4 m$ per project per year equivalent to about $17 \%$ of the value of the project (NAO, 2007). Illustrative is also the case of specialized IT provision where the appropriate use of the facility involves continuous adaptation. Following performance failure and costly contract renegotiation, the HM Treasury in the UK now recommends against the use of PPPs for IT projects (see HM Treasury 2006). Examples of PPP failures in IT include the $£ 400 \mathrm{~m}$ Libra project to provide IT systems for magistrates' courts.

\section{Contractual Dynamics}

Section 3.3 was interesting to describe the basic agency problem that occurs at the inception of PPP projects. Those projects are typically long term projects which might cover 20 to 35 years. Over a long lasting project where the quality of durable assets and infrastructures may significantly depreciate, an important issue concerns the extent to which contractors are willing to invest to improve the stock of existing infrastructure in the long-run or whether they prefer to choose management strategies that maintain costs low in the short-run. 


\subsection{The Trade-Off Between Investment and Maintenance}

To analyze the trade-off between investment and maintenance, let us consider a twicerepeated and slightly modified version of our basic procurement model. To focus on the operator's incentives to invest, we assume that the firm gets a basic stock of infrastructure to run off public service on $G$ 's behalf at date $t=1$. Improving this stock requires some extra investment which costs $\frac{a^{2}}{2}$ today but this pays off tomorrow in terms of lowering operating costs by an amount $a$. Another strategy would be to avoid incurring any initial investment and then cutting operating costs with more maintenance.

Costs in each period are respectively given by:

$$
C_{1}=\theta_{0}-e_{1}+\frac{a^{2}}{2}+\varepsilon_{1} \quad \text { and } \quad C_{2}=\theta_{0}-e_{2}-a+\varepsilon_{2}
$$

where the operating cost uncertainty $\varepsilon_{i}(i=1,2)$ is normally distributed with zero mean and variance $\sigma^{2}$, and $e_{i}$ is maintenance effort undertaken at date $i^{31}$

Investing increases accounting costs in the short-run but, because of a positive externality between design and operation, reduces the long-run cost of the service. ${ }^{32}$ Implicit in our formulation is the fact that the cost of investment is not observable to $G$ meaning that it is (at least partly) aggregated with other costs, noticeably the first-period operating costs, in the firm's book. ${ }^{33}$

Finally, and consistently with Section 3, we assume that the stock of new investment has a social value $b_{0}+b a$ with $b>0$. In practice, this simply means that there is a difference between the social and the private returns on investment. Assuming that investment is verifiable, its first-best level satisfies: $a^{F B}=1+b$ whereas $a=1$ would be privately optimal.

For simplicity, there is no discounting.

- Non-Verifiable Investment: Let us turn now to the case where the investment $a$ is non-verifiable and must be induced by $G$ through designing adequate incentives. Denote $t_{i}\left(C_{i}\right)=\alpha_{i}-\beta_{i} C_{i}$ the cost-reimbursement rule used at date $i .^{34}$ Let us first consider the case where $G$ can commit himself to such a two-period contract $\left\{t_{1}\left(C_{1}\right), t_{2}\left(C_{2}\right)\right\}$.

\footnotetext{
${ }^{31}$ In full generality, we could allow uncertainty on operating costs to be time-dependent. In particular, we might give particular attention to the case $\sigma_{2}<\sigma_{1}$ which means that uncertainty on operating costs may decrease over time (due for instance to learning by doing and better assessments of performances).

${ }^{32}$ With respect to Section 3.3, the investment $a$ has no impact on the social value of the assets which remains fixed and equal to $b_{0}$.

${ }^{33}$ In this respect, our formulation differs from that in Section 2 where the cost of the quality-enhancing effort was off the book.

${ }^{34}$ Decomposing the agent's rewards into two different incentive schemes in each period makes presentation somewhat easier especially in view of the no-commitment case that will be analyzed later on. Of course, this class of incentive schemes entails a loss of generality since, contract $t_{2}\left(C_{2}\right)$ does not depend on the first period realization of costs which makes it impossible to use history dependent contracts
} 
Still assuming a quadratic disutility of maintenance effort in each period, the firm chooses its whole array of actions $\left(a^{*}, e_{1}^{*}, e_{2}^{*}\right)$ to maximize its long-run expected payoff:

$$
\left(a^{*}, e_{1}^{*}, e_{2}^{*}\right)=\arg \max _{\left(a, e_{1}, e_{2}\right)}\left(\sum_{i=1}^{2} \alpha_{i}-\beta_{i}\left(\theta_{0}-e_{i}\right)-\frac{\left(1+r \sigma^{2}\right) e_{i}^{2}}{2}\right)-\beta_{1} \frac{a^{2}}{2}+\beta_{2} a .
$$

This leads to the following incentive constraints:

$$
e_{1}=\beta_{1}, \quad e_{2}=\beta_{2}, \text { and } \beta_{2}=\beta_{1} a \text {. }
$$

An interesting benchmark is obtained when $G$ offers the stationary contract with slope $\beta_{u}^{S B}$, i.e., the contract that would be optimal in the absence of any concern on the renewal of the infrastructure. This contract induces a stationary effort $e_{1}=e_{2}=\beta_{u}^{S B}$ and an investment level, namely $a=1$, which is privately but not socially optimal as soon as $b>0$. There is too little investment in renewing infrastructure with such stationary contract. Raising this investment requires modifying the intertemporal pattern of incentives.

Result 11 Assuming full commitment to a long-term cost-reimbursement rule; the optimal long-term contract entails higher powered incentives towards the end of the contract than at the beginning and an inefficient level of investment:

$$
e_{1}^{S B}<e_{u}^{S B}<e_{2}^{S B}, \text { and } a^{S B}<a^{F B}
$$

The intuition behind this proposition is straightforward. To boost the firm's incentives to undertake a non-verifiable investment, $G$ must let $F$ bear less of the costs and enjoy most of the benefits associated to that investment. This is best achieved by offering cost-plus contracts in the earlier periods and fixed-price contracts towards the end of the relationship. ${ }^{35}$ Still, this is not enough to align the private incentives to invest with the socially optimal ones and underinvestment follows.

Remark 3: History-dependent contracts. Let us suppose now that $G$ can commit himself to two-period history dependent contract $\left\{t_{1}\left(C_{1}\right), t_{2}\left(C_{1}, C_{2}\right)\right\}$ where $t_{1}\left(C_{1}\right)=\alpha_{1}-$ $b_{1} C_{1}$ and $t_{2}\left(C_{1}, C_{2}\right)=\alpha_{2}-b_{2} C_{1}-\beta C_{2}$. The benefit of considering this larger class of incentive schemes is well-known since Rogerson (1985), pushing part of the rewards for

whose value in dynamic incentive problems is well-known (see Remark 3 below). Alternatively, one could view the overall intertemporal incentive scheme $\sum_{i=1}^{2} \alpha_{i}-\beta_{i} C_{i}$ as being offered upfront by the government with all payments being made at the end of the period once the whole realizations of all first- and second-period costs are then known.

${ }^{35}$ In a model that departs from modeling any incentive issues, Goncalves and Gomes (2007) show that a private operator may have an incentive to boost his maintenance effort towards the end of the concession length to meet a predetermined target. 
a good cost realization in the first period towards the second one improves the trade-off between risk and incentives in this first period. ${ }^{36}$ To see how and to check the robustness of our earlier results, observe first that, given the history-dependent contract above, the agent chooses his effort array $\left(e_{1}, e_{2}, a\right)$ so that:

$$
e_{1}=b_{1}+b_{2}=\beta_{1}, \quad e_{2}=\beta_{2}, \text { and } \beta_{2}=\beta_{1} a \text {. }
$$

For a given incentive intensity $\beta_{1}$ the risk borne by the agent over the two periods is better spread when half of those incentives are pushed to the second period, i.e., when $b_{1}=b_{2}=\frac{\beta_{1}}{2}$. Everything happens as if the first period variance on costs was lowered by one half. This implies high-powered incentives to reduce costs in the first period and an unambiguously increase in welfare. But, this welfare improvement has a detrimental impact on investment which becomes less attractive than improved maintenance.

Remark 4: Non-stationary environments. Learning about operating costs over time could be modeled by allowing the noise on the firm's maintenance effort to diminish over time. This effect also goes towards having higher powered incentives in later periods of the relationship which boosts incentives to invest.

Similarly, in the case of a growing demand, having growing operating costs in the second-period may also call for greater returns on maintenance as time goes on. This nonstationary contract also requires higher powered incentives in later stages which boosts investment.

Remark 5: Ownership transfer. It is straightforward to extend the framework above to the case where the firm would enjoy some residual value when owning the asset during the life of the contract. Using the notations of Section 3.3, this would amount to introduce a residual value worth $\gamma s a$ with $s \neq 0$ (whereas our analysis above has supposed $s=0$ ). Of course, there is still not enough investment because of the hold-up problem ex post. However, private ownership still boosts incentives to invest and is thus complementary to a shift of second-period contracts towards fixed-prices.

Remark 6: On-going investments. Consider the case where the effect of a new investment depreciates over time. The power of the incentive scheme must decrease over time to optimally trade off incentives and risk insurance. As investments have been made earlier in the past, the firm will rely more on maintenance to keep operational costs low.

\footnotetext{
${ }^{36}$ History dependent contracts can also help to address adverse-selection problems. In Lewis and Sappington (1997), for example, the power of the incentive scheme decreases with early performance to reduce agent's incentives to understate ability in the first period.
} 


\subsection{Cost Overruns}

Long-term contracting takes place under major uncertainty on the realizations of future costs and demand. In infrastructure projects and maybe due to competitive pressures in awarding projects, contractors are often overly optimistic in estimating future costs, as empirically shown by Flyvbjerg, Skamris Holm and Buhl, (2002) and Gannuza (2007). Based on a sample of 258 transportation infrastructure projects worth US\$90 billion and representing different project types, geographical regions, and historical periods, the authors found with overwhelming statistical significance that the cost estimates used to decide whether such projects should be built are highly and systematically misleading. Following costs overruns, long-term contracting may be subject to significant renegotiation in those environments. Firms may obtain a tariff increase or an increase in the number of cost components passed through tariffs, a reduction in their payment to the public sector and delays and reduction in investments.

To model cost overruns in a nutshell, we will simplify the modeling of Section 7.1, neglect the investment issue or the building stage of contracting and instead focus only on the hazard coming from uncertainty on costs. To model this uncertainty, we follow equation (24) and the description of cost realizations that follow.

Although, it may not be known ex ante at the time of contracting, the base cost level $\theta_{0}$ is later on privately observed by the firm so that there is now asymmetric information. Asymmetric information allows us to consider the strategic incentives of a firm to exaggerate its costs and pretend that costs overruns occur along the course of the contract. To model asymmetric information between the operator and the government, we assume now that costs can be written as:

$$
C=\tilde{\theta}_{0}-e+\varepsilon
$$

where we suppose that the base cost level $\tilde{\theta}_{0}$ is random and may be either high, $\theta_{0}=\bar{\theta}$ with probability $1-\nu$ or low, $\theta_{0}=\underline{\theta}$ with probability $\nu($ denote $\Delta \theta=\bar{\theta}-\underline{\theta}>0)$.

An incentive mechanism must now not only induce the firm to choose a high level of effort but also to induce it to reveal private information ex post, once it knows it. From the Revelation Principle, there is no loss of generality in restricting the analysis to direct revelation mechanisms which consist of a pair of contracts $\left\{\left(\alpha\left(\hat{\theta}_{0}\right), \beta\left(\hat{\theta}_{0}\right)\right)\right\}_{\hat{\theta}_{0} \in\{\underline{\theta}, \bar{\theta}\}}$ stipulating a fixed fee $\alpha\left(\hat{\theta}_{0}\right)$ and a share $\beta\left(\hat{\theta}_{0}\right)$ of the cost borne by the firm as a function of its report $\hat{\theta}_{0}$ on its innate base cost level. Since, for any slope of the incentive scheme $\beta\left(\hat{\theta}_{0}\right)$, the firm always choose an effort level given by $e=\beta\left(\hat{\theta}_{0}\right)$, we may define the certainty equivalent of the firm's expected utility when knowing $\theta_{0}$ as:

$$
U\left(\theta_{0}\right)=\max _{\hat{\theta}_{0} \in\{\underline{\theta}, \bar{\theta}\}} \alpha\left(\hat{\theta}_{0}\right)-\beta\left(\hat{\theta}_{0}\right) \theta_{0}+\frac{\left(1-r \sigma^{2}\right) \beta^{2}\left(\hat{\theta}_{0}\right)}{2} .
$$


Taking the profile of rents and slopes of the incentive schemes $\left\{\left(U\left(\hat{\theta}_{0}\right), \beta\left(\hat{\theta}_{0}\right)\right)\right\}_{\hat{\theta}_{0} \in\{\underline{\theta}, \bar{\theta}\}}$ as the true primitives of our problem allows to write the truthtelling constraint for an efficient firm as: ${ }^{37}$

$$
U(\underline{\theta}) \geq U(\bar{\theta})+\Delta \theta \beta(\bar{\theta})
$$

This constraint is necessary to avoid strategic cost overruns, i.e., incentives for the contractor to inflate his costs.

Note again that the optimal solution consisting in offering a rent/effort profile given by

$$
U^{*}\left(\theta_{0}\right)=0 \text { and } e^{*}\left(\theta_{0}\right)=e_{u}^{S B}
$$

that would be offered had $\theta_{0}$ been contractible can no longer be implemented because an efficient firm would exaggerate strategically its costs. Cost overruns are then an equilibrium phenomenon for such badly designed contract.

To avoid cost overruns, the truthtelling constraint (26) must be binding at the optimum. This requires to create some risk in terms of the certainty equivalents that the firm may get ex post when knowing its innate cost. This increases the risk-premium that society has to bear to induce the firm's participation and it requires to make the firm's payoff less sensitive to the value of its innate costs. This is obtained by distorting downward $e(\bar{\theta})$ below its complete information value, i.e., by giving to an inefficient firm a contract tilted towards a cost-plus contract. The cost of such contract is low powered incentives, but its benefits is that it prevents efficient firms to engage in strategic cost overruns.

We can summarize the analysis as:

Result 12 With ex ante uncertainty and ex post asymmetric information on the realization of future costs, strategic cost overruns are a concerns. The optimal menu of incentive contracts that prevent cost overruns calls for less powered incentives to the less efficient firm and incomplete insurance vis-à-vis the realizations of the innate cost level:

$$
U^{S B}(\underline{\theta})>0>U^{S B}(\bar{\theta}) \text { and } e^{S B}(\underline{\theta})=e_{u}^{S B}>e^{S B}(\bar{\theta}) .
$$

Remark 7: Cost overruns and bundling. Of course, reducing the powered of incentives on cost management to avoid strategic cost overruns makes it less valuable to bundle construction and management in an extended multi-task version of the model that would follow Section 2. This does not at all mean that bundling is no longer optimal. Indeed, cost overruns also occur with the more traditional mode of contracting and would shift

\footnotetext{
${ }^{37}$ We only focus here on the relevant upward incentive constraints where the low cost firm wants to exaggerate its innate cost.
} 
the power of incentives in cost management exactly in the same direction. We conjecture that a priori, a positive externality between construction and management would still be conductive to bundling even with cost uncertainty. ${ }^{38}$

Remark 8: Cost overruns, renegotiation and the soft budget constraint. The optimal contract found above is not renegotiation-proof once $\theta_{0}$ is known. Indeed, to induce revelation information by the most efficient firm, this contract requires that an inefficient one makes a loss. This creates an incentive for the least efficient firm to stop the ongoing project if its innate costs turn out to be high. Anticipating this outcome, the principal may not be able to refrain from instilling more subsidy to ensure that even the worst firms will break even; another instance of the soft budget constraint fallacy. Such possibility for renegotiation is thus akin to assuming that the firm is protected by a pair of interim participation constraints ensuring it breaks even for each realization of its innate costs:

$$
U\left(\theta_{0}\right) \geq 0 \quad \forall \theta_{0}
$$

Such constraints harden the trade-off between incentive and participation constraints. It can be easily seen that only the firm with type $\underline{\theta}_{0}$ obtains now a positive expected payoff and the corresponding distortion of his incentive contracts are exacerbated leading to a large effort distortion given now by: ${ }^{39}$

$$
e^{S B}(\bar{\theta})=\frac{1}{1+r \sigma^{2}}\left(1-\frac{\nu}{1-\nu} \Delta \theta\right) .
$$

\subsection{Related Literature and Applications}

Literature : The literature on intertemporal incentive problems under moral hazard is huge but most of it assumes separability between the benefits and costs of working on a project in different period stressing the role of history dependent contracts to smooth incentives. $^{40}$

The seminal paper on intertemporal effort allocation in the presence of incentive problems is Lambert (1984), who showed that when the project has time separable, mutually independent returns each subperiod, a risk-averse agent will smooth his effort choice to reduce variance in his consumption. This is in contrast to the first-best, where each period's effort is independent of previous periods' output.

\footnotetext{
${ }^{38}$ The key logic behind that conjecture is that the truthtelling incentive constraint is "orthogonal" to the moral hazard incentive constraint. Suppose instead that, the firm has private information on the size of the externality across tasks and that cost overruns come from the overestimation of that externality. Then inducing truthtelling requires reducing the benefit of bundling tasks which may justify unbundling. We leave the investigation of those issues for further research.

${ }^{39}$ Again assuming that $1>\frac{\nu}{1-\nu} \Delta \theta$ to maintain a positive effort.

${ }^{40}$ See Laffont and Martimort (2002, Chapter 8) and the references therein.
} 
Laffont and Tirole (1993, Chapter 8) proposed an adverse selection model with repeated auctions of incentive contracts which shares many features of our model, most noticeably the shift towards higher powered incentives over time. An incumbent firm invests in period 1 but, because of contract renewal, may lose the benefits of its investment if it is not granted the new contract for date 2 . They particularly focused on the necessary bias towards the incumbent as an incentive tool to secure investment and show that this bias matters all the more that investment is not easily transferable. A major result of their analysis is also that incentives to invest are fostered with incentive schemes which are higher powered over time. Our pure moral hazard model can be viewed as providing a simplified version of the same insight.

Higher effort over time is also found by Ray (2007) who studied the value of interim performance evaluations and their effect on the intertemporal effort allocation. He built a two-period model in which both periods' efforts contribute only to the single final outcome and first-period effort is useless unless second-period effort also occurs. Performance evaluations increase efficiency by providing the option to end projects with low early returns and the agent to work harder in later stages because of the risk of termination. This result holds under a variety of scenarios: When the worker has unknown ability, when the outside options vary with output, and in an agency context with a risk-neutral principal and a risk-averse agent.

In non-agency settings different insights are obtained. In line with the career concerns literature, Lewis (1986) shows that reputational concerns lead firms to choose higher effort in earlier stages of their procurement contract in order to send favorable signals to the principal regarding their productivity and avoid that project be terminated too soon.

Dewatripont and Legros (2005) argue that ex ante competition between potential consortia may limit the extent of cost overruns and that introducing a third-party (typically outside shareholders or creditors) in a PPP contract may improve monitoring which limits cost overruns as well.

Applications: Empirical evidence on effort allocation in long-term projects shows that effort rises over time. Projects within firms often run beyond deadlines and most resources are increased towards the final stages (see Marshall and Meckling (1962) and Mansfield et al. (1995)). Actual costs often significantly exceed cost estimates used to decide whether public projects should be built.

PPPs are not immune to cost overruns, though no clear evidence exists as to whether cost overruns under PPPs are more or less likely than under traditional procurement. In the UK, with traditionally procured contracts, in 73 per cent of central government's construction projects the price to the public sector had exceeded the contractors' tender price and the project ran over budget; actual costs were between 2 and 14 per cent above 
estimates. The equivalent figure with PFI was 22 per cent although that was due to the private companies bearing the cost increase rather than the cost increase not occurring (NAO, 2003b). Examples of cost overruns under PPP also include the disastrous case of Metronet, the private tube contractor for London Underground, whose cost overruns lead it to bankruptcy.

Whilst risk allocation in PPPs generally forces the contractor to bear a significant part of the construction and operational risks, the actual risk allocation may differ from what was originally planned. Government are providers of last resort and contractors are aware that public authorities cannot afford prolonged service disruption. The re-tendering of a PPP contact is a long and costly process. Also, as the case of London Underground points out, a market for secondary contracts may not always exist. In fact very few PPP contracts have been pre-maturely terminated. The Channel Tunnel Raillink is one example of the government bailing out the PPP contractor. More generally, empirical evidence supports that risk allocation in practice often departs from what laid out in theory (see e.g. Lobina and Hall, 2003). As stressed by The World Bank, "whether PPPs perform better than full provision by state-owned enterprises depends in particular on whether performance risk is effectively shifted from taxpayers to the private shareholders of the company that enters into a concession-type arrangement" (World Bank, 2002: 23-24).

\section{The Role of the Institutional Framework: Regula- tory and Political Risks}

The non-stationary path of incentives described in Result 11 is of course highly dependent of $G$ 's ability to commit to increase subsidies in the second period to reward $F$ 's initial investment. Assume now that such commitment power is absent and that renegotiation takes place at date 2 with $G$ still having all bargaining power at that stage and extracting, through an adequate fee, all surplus that $F$ could withdraw from renegotiation.

When date 2 comes along, $F$ 's investment $a^{0}$ is sunk and the second period cost reimbursement rule is renegotiated to reach the optimal trade-off between maintenance effort and insurance that would arise in a static context, i.e., conditionally on the investment level $a^{0}$ which was previously sunk. ${ }^{41}$ This yields the standard expressions for the second

\footnotetext{
${ }^{41}$ One word of clarification on the space of contracts allowed is needed at this stage. Indeed, at date 2, the investment level $a$ is private information for the firm. This suggests two things: First, the second period renegotiated contract should allow for screening this piece of information; second, anticipating this screening possibility the firm should create endogenous uncertainty by randomizing among several possible levels of investments. This would certainly bring our analysis closer to the framework of renegotiation under moral hazard due to Fudenberg and Tirole (1990) but at the cost of much complexity. Even if such larger class of second period contracts was allowed, we feel rather confident that the insight that we develop in this section, namely the sytematic move towards cost-plus contracts, would be preserved.
} 
period maintenance effort and the slope of the renegotiated incentive scheme:

$$
\beta_{2}^{0}=e_{2}^{0}=e_{u}^{S B}=\frac{1}{1+r \sigma^{2}} .
$$

Under limited commitment, $G$ can still adjust the second-period fixed-fee to extract all surplus of the firm given his expectation over the investment level $a^{0}$ at this date and, of course, expectations are correct in equilibrium.

Anticipating the slope of date 2 incentive scheme, and knowing also the slope of the first-period incentive scheme, $F$ chooses his investment so that

$$
e_{u}^{S B}=e_{1} a .
$$

With an opportunistic principal, welfare is lower than with full commitment. Moreover, the second-period contract entails lower powered incentives than under full commitment because the second-period incarnation of $G$ does not take into account the impact of the contract he offers on the firm's incentives to invest at date 1. Since $e_{2}^{0}=e_{u}^{S B}<e_{2}^{S B}$, (28) implies that the firm enjoys less of the benefits of investment. To maintain incentives for investment, the firm must be even more reimbursed for its first-period costs than under full commitment which moves first-period incentives even further towards cost-plus contracts.

Result 13 With an opportunistic principal, investment is lower and cost-reimbursement rules are even more tilted towards cost-plus contracts in both periods than under full commitment:

$$
e_{1}^{0}<e_{1}^{S B}, \quad e_{2}^{0}<e_{2}^{S B} \text { and } a^{0}<a^{S B} .
$$

Assume now that renegotiation takes place at date 2 only with probability $p$. This might model settings where the identity of the government may change between dates 1 and 2 with some probability due to elections or where exogenous events occur that induce the current government to renege. In some cases, PPP contract clauses seek to insure the private operator against aggregate risks, but episodes have occurred where governments have reneged on these clauses when a severe macroeconomic crisis occurred. The assumption of limited commitment fits quite well settings with weak enforcement power which may characterize developing countries.

In our setting, when date 2 comes along, $F$ 's investment $a^{0}$ is sunk and with probability $p$ the second period cost reimbursement rule is renegotiated to reach the optimal trade-off between maintenance effort and insurance conditionally on the investment level $a^{0}$. This yields an expression of the firm's incentive constraint which mixes (A.12) and (28):

$$
p e_{u}^{S B}+(1-p) e_{2}=e_{1} a .
$$


The effort levels in this model with political risk are intermediary between the full commitment and the case of an opportunistic principal viewed above.

Result 14 An increase in regulatory risk (i.e., p greater) lowers incentives for investment in asset quality and induces more low powered incentives.

Literature : The model above considers a renegotiation led by the government with the possibility of breaking an initial agreement. In a sense, the intertemporal incentive scheme is thus closer to a sequence of short-term contracts. In a two-period principal-agent model with short-term contracting and pure adverse selection, Laffont and Tirole (1993, Chapter 9) formalized the so-called "ratchet effect". This effect refers to the possibility that an agent with a high performance today will tomorrow face a more demanding incentive scheme, an intertemporal pattern of incentives similar to the one highlighted in Sections 7 and 8 above. The ratchet effect leads to much pooling in the first period as the agent becomes reluctant to convey favorable information early in the relationship. In our model the emphasis is on moral hazard, and the corresponding pattern of incentives induces the agent to invest less in early periods. In the context of PPP contracts, this effect partially nullifies the benefits of bundling and suggests that PPPs should be preferred in stable institutional environments.

Closer to the analysis of Section 8 but still in a pure adverse selection framework, Aubert and Laffont (2002) analyzed the mechanism through which a government can affect future contracting by distorting regulatory requirements to take into account possible political changes and subsequent contract renegotiation. Assuming that the current contract binds all future governments, imperfect commitment yields two main distortions. First, the initial government will delay the payment of the information rent to the second period, thereby free-riding on the cost of producing a higher quantity and leaving higher rents. Second, the degree of information revelation in the first period will be strategically determined to affect the beliefs of the new government. ${ }^{42}$

A number of political motives have been proposed to explain the interests of the publicsector party itself in reneging PPP contracts. The government may increase its chances to be re-elected by expanding spending or by promoting investment in public works that create jobs and boost economic activity (Guasch, 2004). By reneging, the government may also circumvent the opposition's scrutiny and reap the political benefits resulting from higher present spending, e.g. a higher probability of being re-elected (Engel, Fisher and Galetovic, 2006).

\footnotetext{
${ }^{42}$ Other kinds of political risks have been considered in the literature. For instance, Che and Qian (1998) use the property rights approach to show that relinquishing firms' owenrship to local governments may help in a context with insecure property rights where a national government may expropriate owners.
} 
Applications: Institutional quality plays a critical role in the provision of public services by the private sector. Hammami, Ruhashyankiko and Yehoue (2006) indeed found that private participation (in the form of PPP, privatization or traditional procurement) is more prevalent in countries with less corruption and with an effective rule of law. For PPP contracts the benefit of whole-life management cannot be realized in the absence of strong governance and minimal risk of unilateral changes of contract terms by the government.

Governments' failure to honor the terms of concession contracts is a pervasive phenomenon. In Latin America and Caribbean Countries, it is common for a new administration to decide not to honor tariffs increase stated in the concession contract granted by previous administrations. Examples include the Limeira water concession in Brazil which was denied a tariffs adjustment provided by a contract signed by a previous administration. There are also cases where legislation was passed to nullify contractual clauses. The Buenos Aires water concession indexed local-currency denominated tariffs to the US dollar to protect the contractor against currency risk. However, after a devaluation of the local currency, Congress passed an economic emergence law that nullified these guarantees (Lobina and Hall, 2003). Using a sample of 307 water and transport projects in 5 Latin American countries between 1989 and 2000, Guash, Laffont and Straub (2006) found that $79 \%$ of the total government-led renegotiations occurred after the first election that took place during the life of the project. In many cases the central or local government during a re-election campaign decided in a unilateral fashion to cut tariffs or not to honor agreed tariff increases to secure popular support.

Political risk has also played a crucial role in Central and Easter Europe. As reported by Brench, Beckers, Heinrich, and von Hirschhausen, (2005), a major obstacle to the PPP policy in Hungary was the frequent change in political attitudes towards PPPs and user tolls. Since 1990 each change in government resulted in a different attitude and a different institutional framework for PPPs.

The impact of regulatory risk in PPPs is significant as it discourages potential investors and raises the cost of capital and the risk-premium (higher tariffs, or smaller transfer price) paid for a PPP contracts. Guasch and Spiller (1999) estimate that the cost of regulatory risk ranges from 2 to $6 \%$ age points to be added to the cost of capital depending on country and sector. An increase of $5 \%$ age points in the cost of capital to account for the regulatory risk leads to a reduction of the offered transfer fee or sale price of about $35 \%$ or equivalently it requires a compensatory increase in tariffs of about $20 \%$. Regulatory risk also discourages investors. In the $£ 16$ billion London Underground project of 2002-03 a high level of political controversy made lenders nervous, with the result that $85 \%$ of the debt had to be guaranteed by the public sector at a fairly late stage in the procurement process. 
Renegotiation by the government of concession contracts in Latin American and Caribbean Countries is also widespread. Considering a compiled data set of more than 1,000 concessions granted during 1985-2000, Guash (2004) showed that $30 \%$ of the concessions were renegotiated and in $26 \%$ of the cases, the government initiated the renegotiation. Using a data set of nearly 1000 concessions awarded from 1989 to 2000 in telecommunications, energy, transport and water, Guash, Laffont and Straub (2008) showed that the probability of firm-led renegotiation is positively related to the characteristics of the concession contract among other things. Firm-led renegotiation on average tend to favor contractors. Guash, Laffont and Straub (2006) showed that the role of an experienced and independent regulator (or in general the quality of bureaucracy) is especially important in contexts characterized by weak governance and high likelihood of political expropriation. In LAC countries, regulatory agencies were rarely given training and instruments adequate to their mandate and even lacked political support from the government.

To improve governance, a number of countries have created dedicated PPP units centre of expertise - to manage the contract with the private contractor. ${ }^{43}$ Different approaches have been taken with regard to the governance of these units as some of them have been set up within the public sector (e.g. Central PPP Policy Unit in the Department of Finance 1 in Ireland or the Unita' Tecnica della Finanza di Progetto in Italy), others outside (Partnership UK in the UK which is a joint venture between the public and private sector with a majority stake held by the private sector).

\section{Conclusions}

PPPs are being used for building, operating and financing infrastructure in transport, water, energy, health, education, waste management and so on. Notwithstanding the policy relevance, still little theoretical and empirical work has been carried on the topic. In this paper we have reviewed and unified in a common and flexible framework the existing literature on PPPs in an attempt to fill this gap.

Our analysis has pointed at the efficiency gain that PPP arrangements can bring over traditional forms of procurement, but it has also emphasized how PPPs may be unsuitable in a variety of circumstances. The bundling of project phases that characterizes PPPs provides incentives to the private contractor to take into account the long-term project costs, from building to maintenance and operation. When the externality across project stages is positive, this improves incentives and, through appropriate risk transfer, yields

\footnotetext{
${ }^{43}$ Bennett and Iossa (2006b) use an incomplete-contract approach to compare contract management by a public-sector agency with delegation of contract management to a PPP that is a joint venture between private and public sector agents. They show that delegation may be desirable to curb innovations that reduce the cost of provision but also reduce social benefit.
} 
better quality and less expensive projects. We have seen how this holds under a large class of schemes where complete contracts contingent on operating costs can be signed with both the builder and the operator. But, with a negative externality across project stages, bundling may increase agency costs, making traditional forms of procurement preferable. PPP contracts also lack the flexibility to adjust to new circumstances, user needs, or technologies, which points to the unsuitability of PPPs in very uncertain environments.

Thus our analysis suggests that PPPs are more beneficial when a better quality of the infrastructure can significantly reduce cost at the operational stage (including maintenance cost), when infrastructure quality has a great impact on the quality of the service, and when demand for the service is stable and easy to forecast. This points to the suitability of PPPs in the transport and water sectors, where infrastructure quality is key and demand is relatively stable, whilst it suggests that PPPs are less likely to deliver efficiency gains for nursing homes and schools, where service quality is mainly determined by human capital investment, or for IT services, where demand evolves quickly over time.

We have seen that in a PPP contract, although this is not specific to PPPs, satisfaction of consumer's needs and better service quality can be incentivized through the allocation of demand risk and the choice of contract length. In particular, the contractor should bear more demand risk in sectors such as transport, where users pay for the service and demand levels are affected by the contractor's effort. Contractors should bear less risk in sectors such as prisons, where users do not pay and usage is mainly determined by government's policy. Contract length should be higher in sectors where demand risk is lower, as in the water sector as opposed to the transport sector. Financially free-standing projects can bring the additional cost that contract length must be increased to allow the firm to recoup its initial investment, which results in excessive risk transfer. Thus, welfare under PPPs is higher when service quality is verifiable, demand risk is low or the firm can diversify risk, and when there are government contributions or the initial capital investment is low. Recourse to private finance can however result in improved incentives for the operator if lenders bring their expertise in monitoring the operator's effort. In this respect, PPPs might be suitable also for high capital value projects. ${ }^{44}$

Bundling of project phases and long-term contracting allow PPPs arrangements to provide efficient long-term incentives and to optimize the trade-off between investment and maintenance along the life of the project. This helps to prevent cost overruns but it requires institutions with strong commitment power. As the risk of regulatory opportunism increases, the case for PPPs is weaker.

Two important issues have been left out of the analysis. The first relates to the award procedure. As PPP contracts must cover the design, building, operation and

\footnotetext{
${ }^{44}$ Although we have not fully explored this aspect.
} 
finance of the infrastructure, scoring rules need to account for a variety of quality and cost dimensions. Further, communication between procurement authority and potential contractors is needed to match project proposals with authority's needs. In Europe, the auction procedure for awarding PPP contracts, the so-called "Competitive Dialogue", was indeed designed to combine communication with competition. ${ }^{45}$ Research on the topic however remains limited. ${ }^{46}$

Second, beyond the case of regulatory risk, we have been silent about much of the institutional contexts in which PPP contracts are designed. There are at least two aspects that deserve more attention in this respect. The first one is related to the internal organization of the public sphere and its consequences on the likely important delay in having the various public entities involved (local governments, the central State, various Ministries) agreeing on a public demand. ${ }^{47}$ The second important omission of this paper on the political economy side is that we disregarded the issue of collusion between the contracting agency and the firm, though some research exists on the topic. In Martimort and Pouyet (2008) for instance, PPPs are shown to increase the risk of capture for political decision-makers. Indeed, the very reason of the benefits of PPPs is that those contracts allow some efficiency gains that raise the power of incentives, and thus stakes for collusive behavior. ${ }^{48}$ This like other important issues on the design and usefulness of PPP contracts await further research.

\footnotetext{
${ }^{45}$ In private procurement, Bajari, McMillan and Tadelis (2008) show that contracts where communication is important are more likely to be awarded by negotiation than by auction.

${ }^{46}$ See Doni (2007) for a brief discussion of the alternative procedures for PPP contracts.

${ }^{47}$ See Dobrescu, Friebel, Grosjean and Robeck (2008) on this issue.

${ }^{48}$ More generally, there exists a literature dealing on the political side of privatization (Shleifer and Vishny (1994), Bennedsen (2000), Laffont (2005, Chapter 3) and Martimort and Straub (2007) among others). Although its focus is not on PPPs per se, some of its lessons would certainly apply.
} 


\section{References}

[1] Armstrong, M. and D. Sappington (2006) "Regulation, Competition and Liberalization," Journal of Economic Literature, vol. 44: 325-366.

[2] Arthur Andersen and Enterprise LSE (2000), Value for Money Drivers in the Private Finance Initiative. London: The Treasury Taskforce.

[3] Arve, M. (2007), "Multiperiod Contracting and Uncertainty," Mimeo Toulouse School of Economics.

[4] Aubert, C. and J.J. Laffont (2002), "Political Renegotiation of Regulatory Contracts," Mimeo IDEI, Toulouse.

[5] Athias, L. (2008), "Political Accountability, Incentives and Contractual Design of Public-Private Partnerships," Mimeo ATOM, Paris.

[6] Bajari, P. and S. Tadelis (2001), "Incentives versus Transaction Costs: A Theory of Procurement Contracts," RAND Journal of Economics, 32: 387-407.

[7] Bajari, P., McMillan, R. and S. Tadelis (2008), "Auctions versus Negotiations in Procurement: An Empirical Analysis," forthcoming in Journal of Law, Economics and Organization.

[8] Barro, R (1990), "Government Spending in a Simple Model of Endogenous Growth," Journal of Political Economy, 98: 103-117.

[9] Bennett, J. and E. Iossa (2006a), "Building and Managing Facilities for Public Services," Journal of Public Economics, 90: 2143-2160.

[10] Bennett, J. and E. Iossa (2006b), "Delegation of Contracting in the Private Provision of Public Services," Review of Industrial Organization, 29: 75-92 Special Issue on Public-Private Partnerships.

[11] Besley, T. and M. Ghatak (2001), "Government versus Private Oownership of Public Goods," Quarterly Journal of Economics, 116: 1343-1372.

[12] Bennedsen, M. (2000), "Political Ownership," Journal of Public Economics, 76: 559581.

[13] Benz, A., P. Grout, and M. Halonen (2001), "What Should the State Buy?" CMPO Working Paper No. 01/40, University of Bristol.

[14] Blanc-Brude, F.(2007), "The Risk-Averse State: The Portfolio Benefits and Costs of Risk Transfer in PPPs," European Investment Bank, Mimeo King's College London. 
[15] Blanc-Brude, F., H. Goldsmith and T. Välilä(2006), "Ex Ante Construction Costs in the European Road Sector: A Comparison of Public-Private Partnerships and Traditional Public Procurement," European Investment Bank, Economic and Financial Reports 2006/01.

[16] Brench, A., T. Beckers, M. Heinrich, and C. von Hirschhausen, (2005), "PublicPrivate Partnerships in New EU Member Countries of Central and Eastern Europe," European Investment Bank, Vol 10, n.2.

[17] CBI, Confederation of British Industry, 2007. "Building on Success: The Way Forward to PFI."

[18] CBO, Congressional Budget Office (2007), "Trends in Public Spending on Transportation and Water Infrastructure, 1956 to 2004," Congressional Budget Office, Pub.No. 2880.

[19] Che, J. and Y. Qian (1998), "Insecure Property Rights and Government Ownership of Firms," Quarterly Journal of Economics, 113: 467-496.

[20] De Bettignies, J.E. and T. Ross (2004), "The Economics of Public-Private Partnerships," Canadian Public Policy/Analyse de Politiques, 30: 135-154.

[21] De Bettignies, J.E. and T. Ross (2007), "Public Private Partnerships and the Privatization of Financing: An incomplete Contracts Approach," Mimeo UBC, Vanvouver.

[22] Dewatripont, M. and P. Legros (2005), "PPPs: Contract Design and Risk Transfer," European Investment Bank Papers, 10: 120-141.

[23] Dobrescu, G., G. Friebel, P. Grosjean and K. Robeck (2008), "The Determinants of Performance in Building Infrastructure in Transition Economies," Working Paper No. 106 ERBD.

[24] Doni, N. (2007), "A Comparison of Alternative Procedures for the Selection of the Private Partner in PPP Projects," Working Papers, Universita' degli Studi di Firenze.

[25] DOT, Department of Transport, (2007), "Strategic Plan for Fiscal year 2006-2011."

[26] EIB, European Investment Bank (2004), "The EIB's role in Public-Private Partnerships (PPPs)."

[27] Ellman, M. (2006), "The Optimal Length of Contracts with Application to Outsourcing," Discussion Paper Universitat Pompeu Fabra. 
[28] Engel, E., R. Fisher and A. Galetovic (2001), "Least Present Value of Revenue Auctions and Highway Franchising," Journal of Political Economy, 105: 993-1020.

[29] Engel, E., R. Fisher and A. Galetovic (2006), "Renegotiation Without Holdup: Anticipating Spending in Infrastructure Concessions," Cowles Foundation Discussion Paper 1567.

[30] Engel, E., R. Fisher and A. Galetoic (2007), "The Basic Public Finance of PublicPrivate-Partnerships," Mimeo, Department of Economics, Yale University.

[31] Flyvbjerg, B., M. Skamris Holm, and S. Buhl (2002), "Underestimating Costs in Public Works Projects: Error or Lie?" Journal of the Americal Planning Association, 68: 279-295.

[32] Francesconi, M. and A. Muthoo (2006), "Control Rights in Complex Partnerships," Mimeo.

[33] Fudenberg, D. and J. Tirole (1990), "Moral Hazard and Renegotiation in Agency Contracts," Econometrica, 58: 1279-1319.

[34] Gannuza, J.J. (2007), "Competition and Cost Overruns in Procurement," Journal of Industrial Economics, 55: 633-600.

[35] GAO, General Accounting Office (2004), "Highways Transit Private Sector Sponsorship and Investment in Major Projects Has Been Limited," GAO-04-419.

[36] Goncalves, R. and A. Gomes (2007), "Maintenance Incentives in Highway Concession Contracts," Mimeo.

[37] Grout, P. (1997), "The Economics of the Private Finance Initiative," Oxford Review of Economic Policy, 13: 53-66.

[38] Guash, J.L. (2004), "Granting and Renegotiating Infrastructure Concenssions: Doing it Right," WBI Development studies, the World Bank.

[39] Guash, J.L. and P. Spiller (1999), "Managing the Regulatory Process: Design, Concepts, Issues and the Latin America and Caribbean Story," The World Bank, Washington, D.C.

[40] Guasch, J.L., J.J. Laffont and S. Straub, (2006) "Concessions of Infrastructure in Latin America: Government-led Renegotiations," forthcoming Journal of Applied Econometrics. 
[41] Guasch, J.L., J.J. Laffont and S. Straub (2008), "Renegotiation of Concession Contracts in Latin America: Evidence from the Water and Transport Sectors," International Journal of Industrial Organization, Special Issue on PPPs , 26: 421-442.

[42] Hammami, M., J.F. Ruhashyankiko and E.B. Yehoue (2006), "Determinants of Public-Private Partnerships in Infrastructure," Working Paper No 06/99, International Monetary Fund.

[43] Hart, O. (1995), "Firms, Contracts, and Financial Structure, Clarendon Press, Oxford, 1995.

[44] Hart, O. (2003), "Incomplete Contracts and Public Ownership: Remarks and an Application to Public-Private Partnerships," Economic Journal, 119: 69-76.

[45] Hart, O., A. Shleifer and R. Vishny (1997), "The Proper Scope of Government: Theory and an Application to Prisons," Quarterly Journal of Economics, 112: 111958 .

[46] HM Treasury (2003), PFI: Meeting the Investment Challenge. London: HM Treasury.

[47] HM Treasury (2006), Strenghtening long-term partnerships. London: HM Treasury.

[48] HM Treasury (2007). Standardisation of PFI Contracts, Version 4.

[49] Holmström, B. (1979), "Moral Hazard and Observability," Bell Journal of Economics, 10: 74-91.

[50] Holmström, B. and P. Milgrom (1987), "Aggregation and Linearity in the Provision of Intertemporal Incentives," Econometrica 55: 303-328.

[51] Holmström, B. and P. Milgrom (1991), "Multi-Task Principal-Agent Analyses: Incentive Contracts, Asset Ownership, and Job Design," Journal of Law, Economics and Organization, Special Issue, 24-52.

[52] IMF, International Monetary Fund, (2004), "Public-Private Partnerships," paper prepared by the Fiscal Affairs Department, mimeo.

[53] Iossa, E., G. Spagnolo and M. Vellez (2007), "Contractual Issues in Public-PrivatePartnerships," Report prepared for the World Bank.

[54] IPPR, Institute of Public Policy Research (2001), Building Better Partnerships. London: Institute for Public Policy Research.

[55] King, S. and R. Pitchford (2001), "Private or Public? A Taxonomy of Optimal Ownership and Management Regimes," Mimeo University of Melbourne. 
[56] Laffont, J.J. and D. Martimort (2002), The Theory of Incentives: The PrincipalAgent Model, Princeton University Press.

[57] Laffont, J.J. and J. Tirole (1993), A Theory of Incentives in Procurement and Regulation, MIT Press.

[58] Laffont, J.J. (2000), Regulation and Development, Cambridge University Press.

[59] Lambert, R. (1984), "Income Smoothing as Rational Equilibrium Behavior," The Accounting Review 59: 604-618.

[60] Levin J., and S. Tadelis (2007), "Contracting for Government Services: Theory and Evidence from U.S. Cities," Mimeo, Berkeley.

[61] Levita V. (2008), "Les Fonds d'Infrastructure: Une Nouvelle Classe d'Actifs," Mimeo OFI SPQR.

[62] Lewis, T. (1986), "Reputation and Contractual Performance in Long-Term Projects," RAND Journal of Economics 17: 141-157.

[63] Lewis, T. and D. Sappington (1995), "Optimal Capital Structure in Agency Relationships," RAND Journal of Economics, 26: 343-361.

[64] Lewis T. and D. Sappington (1997) "Penalizing Success in Dynamic Incentive Contracts: No Good Deed Goes Unpunished?" RAND Journal of Economics, 28: 346358.

[65] Lobina, E., and D. Hall (2003), "Problems with Private Water Concessions: A Review of the Experiences in Latin America and Other Regions," in Water Pricing and Public-Private Partnership in the Americas, Inter-American Development Bank

[66] Mansfield, E., J. Schnee and S. Wagner (1995), "Overruns and Errors in Estimating Development Cost, Time, and Outcome," in Innovation, Technology and the Economy: The Selected Essays of Edwin Mansfield, Vol. I, Edward Elgar Publishing Limited, Brookfield, United Kingdom, 86-123.

[67] Marshall, A. and W. Meckling (1962), "Predictability of the Costs, Time, and Success of Development," in R. Nelson ed., The Rate and Direction of Inventive Activity: Economic and Social Factors, Princeton University Press, 61-475.

[68] Martimort, D. (2006), "An Agency Perspective on the Costs and Benefits of Privatization," Journal of Regulatory Economics, 30: 5-44. 
[69] Martimort, D. and J. Pouyet (2008), "Build It Not: Normative and Positive Theories of Public-Private Partnerships," International Journal of Industrial Organization, Special Issue on PPPs , 26: 393-411.

[70] Martimort, D. and W. Sand-Zantman (2007), "Signalling and the Design of Delegated Management Contracts for Public Utilities," Rand Journal of Economics, 37: 763782 .

[71] Martimort, D. and S. Straub (2007), "Privatization and Changes in Corruption Patterns : The Roots of Public Discontent," Mimeo Toulouse School of Economics.

[72] Maskin, E. and J. Tirole (2008), "Public-Private Partnerships and Government Spending Limits," forthcoming in International Journal of Industrial Organization. Special Issue on PPPs , 26: 412-420.

[73] NAO, National Audit Office (2003a). Operational Performance of Prisons. London: National Audit Office, HC700.

[74] NAO, National Audit Office (2003b). PFI Construction Performance. London: National Audit Office, HC371.

[75] NAO, National Audit Office (2007). Improving the PFI Tendering Process. London: National Audit Office, HC149.

[76] Pollock, A. and N. Vickers (2000), "Private Pie in the Sky," Public Finance, 14-20: $22-23$.

[77] Price Waterhouse Coopers (2005), "Delivering the PPP Promise: A Review of PPP Issues and Activity."

[78] Rajan, R. G., and Zingales, L. (1998). "Power in a theory of the firm," Quarterly Journal of Economics, 113: 387-432.

[79] Ray, K. (2007), "Performance Evaluations and Effcient Sorting," Mimeo, Graduate School of Business, University of Chicago.

[80] Rey, P. and B. Salanie (1996), "On the Value of Commitment with Asymmetric Information Econometrica," 64: 1395-1414.

[81] Rogerson, W. (1985), "Repeated Moral Hazard," Econometrica, 53: 69-76.

[82] Rosenau, P. V., ed. (2000). Public-Private Policy Partnerships, MIT Press, Cambridge Mass. and London.

[83] Sadka, E. (2008), "Public-Private Partnerships: A Public Economics Perspective," CESifo Economic Studies, 53: 466-490. 
[84] Sappington, D. and J. Stiglitz (1987), "Privatization, Information and Incentives," Journal of Policy Analysis and Management, 6: 567-582.

[85] Saussier, S. (2006), "Public-Private Partnerships and Prices: Evidence From Water Distribution in France," Review of Industrial Organization, 29, Special Issue.

[86] Shapiro, C. and R. Willig (1990), "Economic Rationales for the Scope of Privatization," in E. Suleiman and J. Waterbury eds. The Political Economy of Public Sector Reform and Privatization, 55-87.

[87] Shleifer, A. (1998), "State versus Private Ownership," Journal of Economic Perspectives, 12: 133-150.

[88] Shleifer, A. and R. Vishny (1994), "Politicians and Firms," Quarterly Journal of Economics, 109: 995-1025.

[89] Välilä, T. (2005), "How Expensive are Cost-Savings? On the Economics of PublicPrivate “Partnerships," European Investment Bank Papers, 10: 94-121.

[90] Välilä, T., T. Kozluk and A. Mehrotra (2005), "Roads on a Downhill? Trends in EU Infrastructure Investment," European Investment Bank Papers 10: 18-39.

[91] World Bank (2002), Private Sector Development Strategy - Directions for the World Bank Group, 9th April 2002 (Washington DC, The World Bank Group), http://rru.worldbank.org/documents/PSDStrategy-April209.pdf).

[92] Yescombe, E. (2007), Public Private Partnerships: Principles of Policy and Finance, Elsevier.

\section{Appendix}

- Proof of Result 2: Aggregating the two relevant incentive constraints in (6) by eliminating the slope of the incentive scheme $\beta$ yields the following expression of $G$ 's problem:

$$
\begin{gathered}
\max _{(a, e)} \quad b_{0}-\theta_{0}+(b+\delta) a+e-\frac{a^{2}}{2}-\frac{\left(1+r \sigma^{2}\right)}{2} e^{2} \\
\text { subject to } a=\delta e .
\end{gathered}
$$

Optimizing yields the effort levels

$$
e_{b}^{S B}=\frac{1+\delta(b+\delta)}{1+\delta^{2}+r \sigma^{2}} \text { and } a_{b}^{S B}=\delta e_{b}^{S B}
$$


and the expression of the expected welfare as:

$$
W_{b}^{S B}=b_{0}-\theta_{0}+\frac{(1+(b+\delta) \delta)^{2}}{2\left(1+\delta^{2}+r \sigma^{2}\right)} .
$$

The comparative statics results on $W_{b}^{S B}$ and $W_{u}^{S B}$ immediately follow.

The exact expressions for efforts under bundling are

$$
a_{b}^{S B}=\delta \frac{(b+\delta) \delta+1}{1+r \sigma^{2}+\delta^{2}}>0 \text { and } e_{b}^{S B}=e_{u}^{S B}+\delta \frac{b\left(1+r \sigma^{2}\right)+\delta r \sigma^{2}}{\left(1+r \sigma^{2}+\delta^{2}\right)\left(1+r \sigma^{2}\right)}>e_{u}^{S B} .
$$

Note that $e_{b}^{S B}$ may be greater than $e_{b}^{F B}$ if $b$ is large enough. For $e_{b}^{S B} \leq e^{F B}$, we need $\delta b \leq r \sigma^{2}$.

- Proof of Result 3: Equation (7) yields the following expression of the expected welfare with complete contracts and unbundling:

$$
W_{u}^{S B C}=W_{u}^{S B}+\frac{\delta^{2}(b+\delta)^{2}}{2\left(\delta^{2}+r \sigma^{2}\right)} .
$$

It is easily seen that the gain from writing complete contracts compared with the setting of Section 3.1 is of order $\delta^{2}$ which is rather small for a weak externality.

When bundling is chosen, a single incentive scheme must incentivize both dimensions of effort. The outcome is the same as in Section 3.1 and $W_{b}^{S B C}=W_{b}^{S B}$. Up to terms of order at least $\delta^{2},(\mathrm{~A} .3)$ can be approximated when $\delta$ is small enough as:

$$
W_{b}^{S B C} \approx b_{0}-\theta_{0}+\frac{1}{2\left(1+r \sigma^{2}\right)}+\frac{b \delta}{1+r \sigma^{2}} .
$$

The result follows.

- Proof of Result 4: Consider first the case of unbundling with the incentive constraints (8). Taking into account the risk-premium involved when contracting with the builder and the operator, G's optimization problem becomes:

$$
\max _{(a, e)} b_{0}-\theta_{0}+e+(b+\delta) a-\frac{\left(1+r \sigma^{2}\right) a^{2}}{2}-\frac{\left(1+r \sigma^{2}\right) e^{2}}{2} .
$$

Optimization leads to:

$$
a_{u q}^{S B}=\frac{b+\delta}{1+r \sigma^{2}}>a_{u}^{S B}=0, \text { and } e_{u q}^{S B}=e_{u}^{S B} .
$$

Consider now the case of bundling taking into account the incentive constraint (23). Since $G$ has all bargaining power in designing the consortium's contract and extracts all its ex ante surplus, G's optimization problem becomes:

$$
\max _{(a, e)} b_{0}-\theta_{0}+e+(b+\delta) a-\frac{a^{2}}{2}-\frac{r \sigma^{2}}{2}(a-\delta e)^{2}-\frac{\left(1+r \sigma^{2}\right) e^{2}}{2} .
$$


The maximand above is greater than under unbundling for a positive externality. The reverse holds for a negative externality.

The optimal effort levels are given by:

$$
a_{b q}^{S B}=a_{u q}^{S B}+\frac{\delta r \sigma^{2} e_{b q}^{S B}}{1+r \sigma^{2}}, \text { and } e_{b q}^{S B}=e_{u q}^{S B}+\frac{\delta r \sigma^{2}\left(b\left(1+r \delta^{2}\right)+r \delta \sigma^{2}\right)}{\left(1+r \sigma^{2}\right) D}
$$

where $D=\left(1+r \sigma^{2}\right)^{2}+r \delta^{2} \sigma^{2}$. It is immediate to check that

$$
a_{b}^{S B}>a_{u}^{S B} \text { and } e_{b}^{S B}>e_{u}^{S B} \text { since } \delta>0 .
$$

- Proof of Results 5 and 6: Under private ownership and unbundling, $G$ can extract all the owner's surplus through an ex ante fee because he has all bargaining power ex ante. Given the effort levels defined in (10) and (11), we get the following expression of social welfare:

$$
\begin{gathered}
W_{u}^{p r}=W_{u}^{S B}+\frac{(b+s+\delta)(1-\gamma) s}{2}-\frac{(1-\gamma)^{2} s^{2}}{8} \\
>W_{u}^{S B}=W_{u}^{p u}
\end{gathered}
$$

so that Result 5 holds.

Under private ownership and bundling, ownership has still some value. Taking into account the incentive constraint (12), observing that $G$ extracts now all ex ante surplus from the consortium by raising the fixed-fee $\alpha$ by an amount that covers the extra net benefit that the owner can withdraw from his investment, and finally, aggregating the two incentive constraints in (12), we obtain the following expression of $G$ 's maximization problem:

$$
\begin{gathered}
\max _{(e, a)} \quad b_{0}-\theta_{0}+(b+s+\delta) a+e-\frac{a^{2}}{2}-\frac{\left(1+r \sigma^{2}\right)}{2} e^{2} \\
\text { subject to } a=\delta e+\frac{(1-\gamma)}{2} s .
\end{gathered}
$$

We use (A.6) to express $G$ 's objective function under unbundling and private ownership before optimization with respect to $e$ as:

$$
W_{b}^{p r}(e)=W_{u}^{p r}(e)+\left(b+\delta+\frac{1+\gamma}{2} s\right) \delta e-\frac{\delta^{2} e^{2}}{2}-\frac{r \sigma^{2} \beta^{2}}{2}
$$

where

$$
W_{u}^{p r}(e)=b_{0}-\theta_{0}+(b+\delta+s) a_{u}^{p r}-\frac{\left(a_{u}^{p r}\right)^{2}}{2}+e-\frac{\left(1+r \sigma^{2}\right)}{2} e^{2} .
$$

The result immediately follows. 
- Proof of Result 7: Taking into account that the government can extract all profit from the firm, the government's problem becomes now:

$$
\max _{a} p_{0}\left(d_{0}+a\right)-\frac{\left(1+r \sigma^{2}\right)}{2} a^{2} .
$$

Immediate optimization yields the second-best value of the operating effort as:

$$
a^{S B}=\frac{p_{0}}{1+r \sigma^{2}}<p_{0} .
$$

Note that $p_{0}$ is the first-best level of effort that the firm would implement under riskneutrality since it could then be made residual claimant for the whole benefit of any revenue-enhancing effort.

To implement the second-best level of effort, the government designs a contract with the following features:

$$
\beta^{S B}=\frac{1}{1+r \sigma^{2}}<1 \text { and } \alpha^{S B}=-\beta^{S B} p_{0} d_{0}+\frac{\left(r \sigma^{2}-1\right)\left(\beta^{S B} p_{0}\right)^{2}}{2} .
$$

The result then follows.

- Proof of Result 8: The social welfare maximizing government is concerned by the social value of the project over its entire life. This gives us the following expression of the government's problem:

$$
\begin{gathered}
\left(\mathcal{P}^{p f i}\right): \max _{(a, T)} p_{0}\left(d_{0}+a\right)-\frac{a^{2}}{2}-\frac{r \sigma^{2}}{2}(1-\exp (-\rho T))^{2} p_{0}^{2}-I \\
\text { subject to (14) and (15). }
\end{gathered}
$$

Suppose first that the investment constraint (15) is slack. The second-best effort level is then easily obtained as (16), from which, we derive the optimal unconstrained length of the franchise as (17). Suppose that $T^{S B}$ is such that (15) does not hold, i.e.,

$$
\left(1-\exp \left(-\rho T^{S B}\right)\right) p_{0} d_{0}+\frac{\left(1-r \sigma^{2}\right)}{2}\left(1-\exp \left(-\rho T^{S B}\right)\right)^{2} p_{0}^{2}<I .
$$

The new duration of the contract must solve:

$$
\frac{\left(1-r \sigma^{2}\right)}{2}\left(1-\exp \left(-\rho T^{S B}\right)\right)^{2} p_{0}^{2}+\left(1-\exp \left(-\rho T^{S B}\right)\right) p_{0} d_{0}=I .
$$

Assuming that $1>r \sigma^{2}$, we immediately derive the expression of the incentive intensity as:

$$
\left(1-\exp \left(-\rho T^{S B}\right)\right) p_{0}=\frac{1}{1-r \sigma^{2}}\left(-d_{0}+\sqrt{d_{0}^{2}+2 I\left(1-r \sigma^{2}\right)}\right) .
$$

This formula yields the comparative static results of Result 8 . 
- Proof of Result 9: Taking into account the risk-premium borne by the firm and the coalitional incentive constraint (21), we obtain the following expression of the government's problem:

$$
\max _{e} b_{0}-\theta_{0}+e-\left(1+r \frac{\sigma^{2} \sigma_{\eta}^{2}}{\sigma^{2}+\sigma_{\eta}^{2}}\right) \frac{e^{2}}{2} .
$$

It is straightforward to derive the optimal effort as

$$
e^{F}=\frac{1}{1+r \frac{\sigma^{2} \sigma_{\eta}^{2}}{\sigma^{2}+\sigma_{\eta}^{2}}} \geq e_{u}^{S B} .
$$

- Proof of Result 10: Consider the case of bundling. The realized expected welfare is still given by (A.7). In particular, when $\delta$ is small, we know that $W_{b}^{S B}-W_{u}^{S B}$ is of order $\delta$.

Consider now the case of unbundling. The optimal effort depends now on $\gamma$. Easy computations yield:

$$
e_{u}^{R}(\gamma)=\frac{\gamma}{1+\frac{r \sigma^{2}}{\gamma^{2}}}<\gamma
$$

The expected welfare becomes:

$$
W_{u}^{R}=b_{0}-\theta_{0}+E_{\gamma}\left(\frac{\gamma^{4}}{2\left(\gamma^{2}+r \sigma^{2}\right)}\right)>W_{u}^{S B}
$$

where the last inequality follows from Jensen inequality and the fact that $\frac{\gamma^{4}}{2\left(\gamma^{2}+r \sigma^{2}\right)}$ is convex in $\gamma$. Note that $W_{u}^{R}$ differs from $W_{u}^{S B}$ by a term of order zero in $\delta$.

- Proof of Result 11: $G$ has still all bargaining power in designing the firm's contract and uses accordingly the intertemporal fixed-fee $\alpha_{1}+\alpha_{2}$ to extract all ex ante surplus from the firm. Aggregating the three incentive constraints (22) into a single one, $G$ 's optimization problem becomes:

$$
\begin{aligned}
\max _{\left(a, e_{1}, e_{2}\right)} 2\left(b_{0}-\theta_{0}\right)+ & \left\{\sum_{i=1}^{2} e_{i}-\frac{\left(1+r \sigma^{2}\right) e_{i}^{2}}{2}\right\}+(1+b) a-\frac{a^{2}}{2} . \\
& \text { subject to } e_{2}=a e_{1} .
\end{aligned}
$$

Denote by $\mu$ the multiplier of (A.12). Observe that the first-order conditions w.r.t. $\left(e_{1}, e_{2}, a\right)$ can be written respectively as:

$$
1-\left(1+r \sigma^{2}\right) e_{1}=\mu a, \quad 1-\left(1+r \sigma^{2}\right) e_{2}=-\mu, \text { and } 1+b-a=\mu e_{1} .
$$

From this, we can express $\left(e_{1}, e_{2}, a\right)$ as functions of $\mu$ :

$$
e_{1}(\mu)=\frac{1-\mu(1+b)}{1+r \sigma^{2}-\mu^{2}}, \quad e_{2}(\mu)=\frac{1+\mu}{1+r \sigma^{2}}, \text { and } a(\mu)=\frac{(1+b)\left(1+r \sigma^{2}\right)-\mu}{1+r \sigma^{2}-\mu^{2}}
$$


which are all positive effort levels when $0 \leq \mu \leq \frac{1}{1+b}$.

Inserting into (A.12), we get that $\mu$ solves:

$$
\varphi(\mu)=\left(1+r \sigma^{2}\right)(1-\mu(1+b))\left((1+b)\left(1+r \sigma^{2}\right)-\mu\right)-(1+\mu)\left(1+r \sigma^{2}-\mu^{2}\right)^{2} .
$$

Note that $\varphi(0)>0>\varphi\left(\frac{1}{1+b}\right)$ so that the latter equation has a root $\mu \in\left(0, \frac{1}{1+b}\right)$, which yields the result.

- Proof of Result 12: Contracting taking place ex ante, i.e., before the firm learns its innate costs, the following ex ante participation constraint must hold:

$$
\nu u(U(\underline{\theta}))+(1-\nu) u(U(\bar{\theta})) \geq 0,
$$

where the firm's Von Neuman-Morgenstern utility is $u(x)=\frac{1}{r}(1-\exp (-r x))$ because of constant risk-aversion.

Being given the social benefit $b_{0}$ of the project, the government's problem can now be written as:

$$
\left(\mathcal{P}^{e a}\right): \max _{(U(\cdot), \beta(\cdot))} b_{0}+E_{\theta_{0}}\left(-\theta_{0}+\beta\left(\theta_{0}\right)-\frac{\left(1+r \sigma^{2}\right) \beta^{2}\left(\theta_{0}\right)}{2}-U\left(\theta_{0}\right)\right)
$$

subject to (26) and (A.13).

Observing that both (26) and (A.13) are binding yields the following expressions of the certainty equivalent for the firm's payoff for each realization of $\theta_{0}$ as:

$$
U^{S B}(\underline{\theta})=\Delta \theta \beta^{S B}(\bar{\theta})+\frac{1}{r} \ln \left(1-\nu+\nu \exp \left(-r \Delta \theta \beta^{S B}(\bar{\theta})\right)\right)>0
$$

and

$$
U^{S B}(\bar{\theta})=\frac{1}{r} \ln \left(1-\nu+\nu \exp \left(-r \Delta \theta \beta^{S B}(\bar{\theta})\right)\right)<0 .
$$

The levels of effort are respectively given by:

$$
e^{S B}(\underline{\theta})=\beta^{S B}(\underline{\theta})=e_{u}^{S B} \text { and } e^{S B}(\bar{\theta})=\beta^{S B}(\bar{\theta})=\frac{1}{1+r \sigma^{2}}\left(1-\frac{\nu \Delta \theta\left(1-\exp \left(-r \Delta \theta e^{S B}(\bar{\theta})\right)\right)}{1-\nu+\nu \exp \left(-r \Delta \theta e^{S B}(\bar{\theta})\right)}\right)<e_{u}^{\varsigma}
$$

